\title{
Sustentabilidade na atividade rural: Um estudo em uma propriedade de pequeno porte no noroeste gaúcho
}

\author{
Sustainability in rural activity: A study in a small property in northwest gaúcho \\ Sostenibilidad en la actividad rural: Un estudio en una pequeña propiedad del noroeste gaúcho.
}

Recebido: 11/12/2021 | Revisado: 15/12/2021 | Aceito: 01/02/2022 | Publicado: 03/02/2022

\author{
Anderson Pretto Birkhahn \\ ORCID: https://orcid.org/0000-0003-0050-6231 \\ Universidade Regional do Noroeste do Estado do Rio Grande do Sul, Brasil \\ E-mail: anderson.birkhahn@sou.unijui.edu.br \\ Cristiane Lelis dos Santos Garito \\ ORCID: https://orcid.org/0000-0001-5514-3242 \\ Universidade Regional do Noroeste do Estado do Rio Grande do Sul, Brasil \\ E-mail: cristiane.garito@sou.unijui.edu.br \\ Euselia Paveglio Vieira \\ ORCID: https://orcid.org/0000-0001-5927-2703 \\ Universidade Regional do Noroeste do Estado do Rio Grande do Sul, Brasil \\ E-mail: euselia@unijui.edu.br \\ Maria Margarete Baccin Brizolla \\ ORCID: http://orcid.org/0000-0002-5120-0729 \\ Universidade Regional do Noroeste do Estado do Rio Grande do Sul, Brasil \\ E-mail: marga.brizolla@gmail.com \\ Mônica Aparecida Ferraz Moreira \\ ORCID: https://orcid.org/0000-0002-9146-6134 \\ Universidade Regional do Noroeste do Estado do Rio Grande do Sul, Brasil \\ E-mail: monicaferraz@uol.com.br \\ Nadine Conrad Dubal \\ ORCID: https://orcid.org/0000-0003-0720-4025 \\ Universidade Regional do Noroeste do Estado do Rio Grande do Sul, Brasil \\ E-mail: ncdubal@terra.com.br \\ Patricia Luiza Schuh \\ ORCID: https://orcid.org/0000-0002-5470-4113 \\ Universidade Regional do Noroeste do Estado do Rio Grande do Sul, Brasil \\ E-mail: patricia.schuh@hotmail.com \\ Roselaine Filipin \\ ORCID: https://orcid.org/0000-0002-3887-5764 \\ Universidade Regional do Noroeste do Estado do Rio Grande do Sul, Brasil \\ E-mail: rosefin@hotmail.com
}

\begin{abstract}
Resumo
A sustentabilidade é um tema que vem crescendo nas discussões e tem sido abordada com bastante intensidade nos estudos acerca da temática. Dada a sua importância, o objetivo do estudo é utilizar um modelo de sustentabilidade específico para organizações pequenas rurais como o caso do MASPPR, o tema é alvo de propostas para discussão na área da agricultura. Este trabalho analisou como os indicadores de sustentabilidade podem auxiliar os produtores rurais a promover melhorias nos processos de gestão e desempenho de modo a torná-las mais sustentáveis, a partir do modelo MASPPR. A pesquisa foi classificada como descritiva, estudo de caso, documental e qualitativa. Para a realização dessa pesquisa utilizou-se de dados coletados a partir dos documentos, observação e de entrevista semiestruturada para complementar os dados obtidos, a partir de um constructo apoiado no modelo MASPPR. Os achados indicam sustentabilidade da propriedade, em torno de 72,08\%. Tal representatividade é possível, visto que todas as ter dimensões analisadas (econômica, social e ambiental), quando observadas de forma individual foram superiores a 50\%, havendo um destaque para a dimensão ambiental, em que a sustentabilidade foi de $100 \%$. Com isso entende-se que saber em que medida os indicadores de sustentabilidades de cada dimensão estão presentes nas atividades econômicas da propriedade rural investigada pode auxiliar quanto a melhoria dos processos de produção, assim como na tomada de decisão com relação a melhorar os seus controles econômicos e financeiros e seus indicadores socioambientais.
\end{abstract}

Palavras-chave: Triple Botton Line; Indicadores; Agricultura. 


\begin{abstract}
Sustainability is a topic that has been growing in discussions and has been addressed with great intensity in studies on the subject. Given its importance, the objective of the study is to use a specific sustainability model for small rural organizations such as the case of MASPPR, the topic is the subject of proposals for discussion in the area of agriculture. This work analyzed how sustainability indicators can help rural producers to promote improvements in management and performance processes in order to make them more sustainable, based on the MASPPR model. The research was classified as descriptive, case study, documentary and qualitative. To carry out this research, data collected from documents, observation and semi-structured interviews were used to complement the data obtained, based on a construct supported by the MASPPR model. The findings indicate the sustainability of the property, around $72.08 \%$. Such representativeness is possible, since all the dimensions analyzed (economic, social and environmental), when observed individually, were greater than $50 \%$, with an emphasis on the environmental dimension, in which sustainability was $100 \%$. With this, it is understood that knowing to what extent the sustainability indicators of each dimension are present in the economic activities of the investigated rural property can help in the improvement of production processes, as well as in the decision making regarding to improve its economic controls. and financial and their socio-environmental indicators.
\end{abstract}

Keywords: Triple Bottom Line; Indicators; Agriculture.

\title{
Resumen
}

La sostenibilidad es un tema que ha ido creciendo en las discusiones y ha sido abordado con considerable intensidad en los estudios sobre el tema. Dada su importancia, el objetivo del estudio es utilizar un modelo de sustentabilidad específico para pequeñas organizaciones rurales como es el caso de MASPPR, el tema es objeto de propuestas de discusión en el área de agricultura. Este trabajo analizó cómo los indicadores de sostenibilidad pueden ayudar a los productores rurales a promover mejoras en los procesos de gestión y desempeño para hacerlos más sostenibles, con base en el modelo MASPPR. La investigación se clasificó en descriptiva, estudio de caso, documental y cualitativa. Para la realización de esta investigación se utilizaron datos recolectados de documentos, observación y entrevistas semiestructuradas para complementar los datos obtenidos, a partir de un constructo sustentado en el modelo MASPPR. Los hallazgos indican la sostenibilidad de la propiedad, alrededor del 72,08\%. Tal representatividad es posible, ya que todas las dimensiones analizadas (económica, social y ambiental), al ser observadas individualmente, fueron superiores al 50\%, con énfasis en la dimensión ambiental, en la que la sostenibilidad fue del 100\%. Con ello, se entiende que conocer en qué medida los indicadores de sostenibilidad de cada dimensión están presentes en las actividades económicas del predio rural investigado puede ayudar en la mejora de los procesos productivos, así como en la toma de decisiones en cuanto a mejorar su economía. controles y financieros y sus indicadores sociales y ambientales.

Palabras clave: Triple Resultado; Indicadores; Agricultura.

\section{Introdução}

Conforme a posição de (Sanches, 1997): “O enfoque da proteção ambiental, desloca, então a dimensão ambiental do âmbito da função de produção para se tornar parte da função da administração”. Segundo (Tachizawa, 2005), os gastos da empresa com proteção ambiental a partir dos anos 80 começaram a serem vistos não como custos, mas com investimentos no futuro e vantagens competitivas.

Para (Ferreira, 2002), a contabilidade ambiental, objetiva fornecer informações adequadas a respeito dos eventos econômicos relacionados ao meio ambiente, permitindo a correta mensuração e avaliação do patrimônio. O problema está em como mensurar e oferecer informações aos gestores, para a tomada de decisão, que possa auxiliar na sustentabilidade das propriedades rurais.

Os produtores rurais tornaram-se mais dependentes de conhecimento, informação e tecnologia para decidir sobre as necessidades de produção. (Oliveira, 1996) afirma que a “informação é um produto de análise dos dados existentes na empresa, devidamente registrados, classificados, e organizados, relacionados e interpretados dentro de um contexto para transmitir conhecimento e permitir a tomada de decisão de forma otimizada"

Entre os papéis que a agricultura familiar assume para o desenvolvimento econômico, pode-se apontar a manutenção da população entre os espaços no campo; a diversificação das economias locais; a preservação do patrimônio sociocultural; a promoção da segurança alimentar; a sua contribuição para a melhoria de vida e a redução da pobreza das famílias produtoras e também contribuições para criar estratégias de produção sustentáveis. Não menos importante, as relações sociais entre os 
produtores e compradores possuem a qualidade de reduzir os custos e inseguranças relacionadas às transações nos mercados locais, refletindo em custos e preços relativos mais baixos (Schneider, 2016; Vian, 2020).

(Bellen, 2002), citando (Tunstall, 1994), reitera que os indicadores possuem cinco principais funções, são elas: avaliação de condições e tendências, comparação entre lugares e situações, avaliação de condições e tendências em relação às metas e aos objetivos, prover informações de advertência e antecipar futuras condições e tendências. Ainda segundo o autor, os sistemas de indicadores de desenvolvimento sustentável precisam ter as seguintes características: indicadores devem ser mensuráveis; ter disponibilidade de dados; os métodos de coleta e processamento de dados, bem como a construção dos indicadores devem ser claros; ter disponíveis os meios para a construção e monitoramento dos indicadores; deve ser financeiramente viável e, por fim, deve ter a aceitação política dos indicadores nos níveis adequados a fim de influenciar as decisões.

A sustentabilidade é definida como: "um princípio que assegura que nossas ações de hoje não limitarão a gama de opções econômicas, sociais e ambientais disponível para as futuras gerações" (Elkington, 2001). Com o crescimento econômico aumenta a desigualdade social e prejuízos ambientais, pois os recursos vão sendo explorados e para que as indústrias funcionem também se utiliza substâncias nocivas e poluentes em seu processo de transformação, assim aumentam as razões para que as empresas procurem meios para diminuir os danos ao meio ambiente e a sociedade (Carvalho \& Stefano \& Munck, 2015; Vale et al., 2020).

Para (Reigota, 2007), a sustentabilidade é um termo que é controverso, esta afirmação está alinhada com (Garcia, 1999), que pensa que a sustentabilidade se opõe-se radicalmente ao desenvolvimento sustentável, basicamente, na ideia dele, ele tem uma interpretação hegemônica que sempre prioriza o desenvolvimento dos moldes capitalistas.

De acordo com (Sachs, 1993), o conceito de sustentabilidade social refere-se ao desenvolvimento e tem por objetivo a melhoria da qualidade de vida da população, procurando diminuir a desigualdade social, ampliar os direitos e garantir acesso aos serviços básicos, como educação e saúde. Para países com problemas de desigualdade e de inclusão social, implica a adoção de políticas distributivas e a universalização de atendimento a esses serviços básicos.

Conforme (Oliveira, et al., 2004) a busca incansável pelo desenvolvimento sustentável e para obter os benefícios, que são de ordem econômico-sociais, serve como um fator de motivação para as empresas, criarem planos que possam usar o estudo e a aplicação em projetos com esse tema. Porém, a forma que pode servir como motivação na preocupação das empresas com a responsabilidade e sustentabilidade social parece que constantemente busca sempre evidenciar a principal busca que é por resultados econômicos. Isso poderia acarretar consequências do capital reputacional que é adquirido através de ações socialmente corretas.

Du Pisani e Wrigley, (2006) afirmam que as raízes que servem como conceitos da Sustentabilidade, elas podem ser mapeadas desde os tempos da Grécia Antiga, porem acaba ganhando destaque na história da humanidade, através de novas questões que são trazidas por meio do avanço tecnológico, o grande aumento do consumo de energia e o volume exponencial da população que ocorreu com a Primeira Revolução Industrial.

Segundo o estudo de (Barbieiri, et al., 2010) ele faz uma comparação entre a relação sobre sustentabilidade e a inovação, o autor tenta abordar a semelhança entre os dois assuntos, para destacar a importância que existe nas empresas para buscar sempre inovações para a empresa se manter sempre no mercado, porém sempre é preciso respeitar as três dimensões que existem na sustentabilidade que são: social, ambiental e a econômica.

Seguindo esse pensando, outro termo que pode ser usado para sustentabilidade, é empregado sempre visando garantir como as ações e as atividades humanas que são utilizadas para suprir as necessidades do ser humano, de maneira para não comprometer nas próximas gerações. "A sustentabilidade está exatamente relacionada ao desenvolvimento econômico e material pensando sempre em não prejudicar o meio ambiente. (Santos \& Ferreira, 2011)”. 
Conforme (Boff, 2015) a solução para quase todos os problemas ambientais é através da sustentabilidade real, efetiva e global, conjugada com o principal princípio do cuidado e da prevenção. Não somente as pessoas, mas também tem as empresas que precisam se preocupar com os processos sustentáveis e que existem políticas para preservação, sempre tendo no pensamento que são essas que mais impactam no meio ambiente (Vale, et al., 2020).

De acordo com (Munck, et al., 2011) o pilar ambiental, se reporta a viabilidade ambiental, e completa que tem respeito pela prevenção dos impactos negativos que são gerados pela empresa nos sistemas que são naturais, em outras palavras, a conservação e o manejo adequado com os recursos naturais. Esse tipo de prática envolve muitos fatores principalmente os cumprimentos legais, ou seja, uma abordagem que é compreensiva sobre as operações organizacionais da companhia. (Jamali, 2006; Vian, 2020).

Segundo Kranjc e Glavic (2005), o pilar ambiental pode se referir a um setor que é muito necessário dentro de uma organização, pois tem uma perspectiva de impacto dentro das operações e produtos que são sobre os sistemas naturais vivos e dos não vivos, que visa procurar minimizar os impactos que são negativos e ampliar os que são positivos, tanto nos processos de saída, quanto nos de entrada. Para (Jamali, 2006), o autor cita que existe uma responsabilidade sobre o meio natural que abrange muito mais do que os cumprimentos legais, e até mesmo mais iniciativas como são os casos da reciclagem ou uso eficiente dos recursos energéticos. Tudo isso precisa envolver uma abordagem que precisa ser compreensiva as operações organizacionais.

Para Elkington (1997) e Werbach (2010) já abordavam sobre este tema, e para eles as empresas precisam verificar quais são as ações e as condições que possam afetar a ecologia do planeta. Pode citar, as mudanças climáticas, a preservação dos recursos naturais e prevenção dos lixos tóxicos. Coral (2002), Catalisa (2003) e Vale, et al. (2020), mencionam que o pilar ambiental se encontra vinculado a utilização dos recursos que são naturais, como o objetivo de sempre minimizar os danos ao meio ambiente, este pilar envolve o comprimento da legislação, diminuir os impactos ambientais, aumentar os produtos que são ecologicamente corretos, fazer a reciclagem correta, a ter uma tecnologia limpa, e estar de olho no tratamento de efluentes e dos resíduos e a forma de utilização sustentável dos recursos que são naturais.

Segundo Garcia (2016), aborda a dimensão ambiental, como aquela que visa buscar a importância da proteção ao meio ambiente, e logo depois, do Direito Ambiental, esse segundo tem como finalidade precípua, sempre garantir a sobrevivência do planeta através da preservação ambiental e da melhora de elementos físicos e químicos que auxiliam para isso, tudo visando sempre ter uma melhor qualidade de vida.

Segundo Martins (2002) o autor considera que existe a degradação ambiental por conta das condições sanitárias ruins, também tem a existência da poluição que é causada pelas pessoas, ou pelo fato da ocupação em fundo de vale, ou até mesmo pelas áreas que são de risco geológico ponderando sobre a necessidade que faz com que previna a poluição, com isso preserva a vida, a capacidade da carga dos sistemas, entre outros fatores.

Segundo Elkington (2001) fala sobre o que o desenvolvimento sustentável precisa atender, seguindo um sistema, a três dimensões essenciais: que são a econômica, a social e a ambiental. O pilar econômico se trata dos problemas financeiros das ações que as empresas passam para o stakeholders; já o pilar social refere-se à participação da manutenção e do aperfeiçoamento do sistema que tratam a respeito dos direitos e das responsabilidades; e por fim o pilar ambiental que defende a conservação e a alocação correta dos recursos naturais sempre visando não ser prejudicial ao meio ambiente.

Para Munck e Borim-de-Souza (2011) os autores explicam que o pilar econômico é sobre a viabilidade econômicofinanceira, e está ligando a vários aspectos como da competitividade, a oferta de empregos, fazer uma busca em novos mercados e sempre visam a lucratividade. O tema trata também sobre como é a capacidade organizacional da empresa apresentar o fluxo de caixa que faz com que consiga a liquidez que é necessária. A sustentabilidade econômica é a responsável pela geração da riqueza, e indica qual é a capacidade para realizar as atividades de maneira que é responsável e visando buscar 
o lucro. (Dyllick \& Hockerts, 2002; Lorenzetti \& Cruz \&Ricioli, 2008; Vale, et al., 2020).

Segundo Elkington (2001), na visão convencional, o pilar econômico se resume em um fator, que é sobre o lucro da empresa, portanto para os contadores realizarem os cálculos, são utilizados apenas os dados numéricos. A abordagem que vai ser feita nesse pilar, entretanto, precisa ser feito uma busca da sustentabilidade econômica dentro da empresa que seja a longo prazo.

O pilar ambiental social se refere sempre a viabilidade social, e também consegue gerir o impacto que a empresa provoca nos sistemas sociais por meio das atividades que são operacionais. Para isso, é feito uma busca para considerar as expectativas de vários grupos sociais que são relacionados com à organização, sempre atento para quando surgir questões que são relacionadas ao desenvolvimento do ser humano, integridade e a ética. (Munck, et al., 2011). Isso se diz respeito ao alcance que tem a igualdade, e a participação de todos os grupos sociais para construir e fazer a manutenção do equilíbrio do sistema, repartindo os direitos e as responsabilidades (Cruz \& Lorenzetti, 2008; Bansi, et al., 2011; Vale, et al., 2020).

Dyllick e Hockerts (2002) fazem o apontamento de que no nível das organizações a sustentabilidade social pressupõe que as corporações precisam adicionar um valor para as suas comunidades, partindo do desenvolvimento de capital humano dos indivíduos e do capital social das comunidades. Ahmed e McQuaid (2005) argumentam que o conceito da sustentabilidade social frisa a admiração de recursos sociais, isso inclui as pessoas e as suas competências e as habilidades, as instituições, os relacionamentos e os valores sociais.

A sustentabilidade social trata das oportunidades para o desenvolvimento de novas habilidades, de novos produtos e de novos processos e de novas capacidades tecnológicas. O critério é direcionado a dois fatores que são a pesquisa e desenvolvimento e do desenvolvimento de carreira. O primeiro aspecto de pesquisa e desenvolvimento serve para avaliar as contribuições que a companhia realiza para fazer o desenvolvimento de novos produtos sustentáveis através de pesquisas e do avanço no desenvolvimento de novos programas, isso faz com que haja inovação nos produtos. Já o segundo aspecto que é o desenvolvimento de carreira ele tem como foco no treinamento dos colaboradores e realizar o aconselhamento de carreira e também de oportunidades para a educação. (Foladori \& Tommasino, 2000; Labuschagne et al., 2004; Vian, 2020).

Neste cenário a questão de estudo é: Como os indicadores de sustentabilidade podem auxiliar os produtores rurais a promover melhorias nos processos de gestão e desempenho de modo a torná-las mais sustentáveis? O objetivo do estudo é utilizar um modelo de sustentabilidade específico para organizações pequenas rurais como o caso do MASPPR, diferente de (Kowaleski, 2019), por estudar especificamente o modelo sugerido por (Maas, et al., 2016) como pouco abordado e por aplicar o modelo em uma propriedade do Noroeste gaúcho, visto que (Vian, 2020), ciou e aplicou o modelo no Paraná.

Maas et al. (2016) faz algumas reflexões importantes e identifica que muito tem sido escrito sobre porque as empresas estão envolvidas em questões de sustentabilidade, no entanto, relativamente pouca pesquisa aborda a questão integrativa como, particularmente, como as empresas podem e integram a avaliação da sustentabilidade, a contabilidade gerencial, controle de gestão e relatórios. Kowaleski (2019), utilizou o modelo de (Oliveira, 2007), para identificar como um conjunto de indicadores para avaliação de sustentabilidade ambiental, social e econômica, podem auxiliar os gestores na melhoria do desempenho de uma organização rural visando a sustentabilidade.

Também Vian (2020) desenvolveu um modelo para avaliar a sustentabilidade de pequenas propriedades rurais (MASPPR) por meio de um modelo multicritério linguístico abordando as dimensões econômica, social e ambiental.

Com isso este estudo se difere dos demais por estudar uma propriedade de pequeno porte, a partir do modelo MASPPR, no Noroeste do Rio Grande do Sul, com características especificas da produção de leite, soja e milho.

\section{Metodologia}

O estudo visa identificar e descrever os principais elementos necessários, para compreender a intensidade de 
sustentabilidade da propriedade rural, a partir da identificação de um conjunto de indicadores, que consideram os pilares sociais, ambientais e econômicos, o que possibilita a análise desses indicadores, auxiliando os gestores a promover ajustes, visando melhorar o desempenho da organização.

Sendo assim, quanto a natureza da pesquisa, essa é uma pesquisa aplicada, visto que os conhecimentos teóricos têm uma aplicação prática focada na solução de problemas específicos, como destacado por (Prodanov \& Freitas, 2013).

Quanto aos seus objetivos, é possível classificar a pesquisa em três grandes grupos: exploratórias, descritivas e explicativas (Gil, 2010). Posto isso, dentre as classificações apresentadas quanto aos seus objetivos, a pesquisa realizada neste estudo classifica-se como descritiva. De acordo com (Prodanov \& Freitas, 2013) o estudo caracteriza-se como sendo descritivo "quando o pesquisador registra e descreve os fatos observados sem interferir neles. Descreve as características de determinada população ou fenômeno ou o estabelecimento de relações entre variáveis".

Em relação aos procedimentos técnicos a pesquisa é classificada como sendo documental considerando a abrangência do conteúdo e com a pesquisa será possível entender o que se passa na propriedade rural, e como a sustentabilidade ambiental e seus indicadores estão interligados.

Outro procedimento utilizado na pesquisa é o estudo de caso, visto que o trabalho é feito em uma propriedade rural, sendo esse o principal objeto de análise. Segundo (Yin, 2001): "o estudo de caso é uma investigação empírica de um fenômeno contemporâneo dentro de um contexto da vida real, sendo que os limites entre o fenômeno e o contexto não estão claramente definidos". (Gil, 2008) explica que o estudo de caso "[...] consiste no estudo profundo e exaustivo de um ou poucos objetos, de maneira que permita seu amplo e detalhado conhecimento [...]".

Quanto a abordagem a pesquisa é qualitativa, para identificar qual é a realidade da propriedade rural, através da coleta de dados e os procedimentos feitos com as informações, fazendo uma interpretação dos fenômenos da pesquisa. Segundo (Richardson, 1999) destaca que "o objetivo fundamental da pesquisa qualitativa não reside na produção de opiniões representativas e objetivamente mensuráveis de um grupo; está no aprofundamento da compreensão de um fenômeno social por meio de entrevistas em profundidade e análises qualitativas da consciência articulada dos atores envolvidos no fenômeno". Por esse motivo, a validade da pesquisa não se dá pelo tamanho da amostra, como na pesquisa quantitativa, mas, sim, pela profundidade com que o estudo é realizado.

A coleta de dados junto à propriedade rural se dá através de entrevista semiestruturada, envolvendo questionamentos básicos, a partir de um constructo apoiados no modelo MASPPR (Modelo para Avaliar a Sustentabilidade de Pequenas Propriedade Ruais), conforme (Vian, 2020), que interessam à pesquisa e que, em seguida, referem-se a interrogativas, que surgem no transcorrer do estudo. Assim, o informante, seguindo espontaneamente sua linha de pensamento e suas experiências cotidianas, influencia a elaboração do conteúdo da pesquisa (Beuren, et al., 2004). A entrevista contempla conversas com os gestores, observação e análise documental, visando trazer informações a respeito do processo produtivo da propriedade, os tipos e quantidades de insumos consumidos, assim como os valores destes, auxiliando na organização através de elaboração de planilhas para levantamento e análise de custos, investimentos, despesas e receitas da propriedade, tendo elementos de análise gerencial na tomada de decisão. Para Marconi e Lakatos (2003) "a observação é uma técnica de coleta de dados para conseguir informações e utiliza os sentidos na obtenção de determinados aspectos da realidade. Não consiste apenas em ver e ouvir, mas também em examinar fatos ou fenômenos que se desejam estudar".

Na concepção de Beuren, et al. (2009) "analisar dados significa trabalhar com todo o material obtido durante o processo de investigação, ou seja, com os relatos de observação, as transcrições de entrevistas, as informações dos documentos e outros dados disponíveis".

Para a análise e interpretação dos resultados, os dados são organizados a partir de quadros e planilhas de modo a conhecer os indicadores que permitem indicar a sustentabilidade na propriedade, visando promover melhorias nos processos de 
gestão e desempenho de modo a torná-las mais sustentáveis. Dentre as várias técnicas de análise de dados na pesquisa qualitativa, Merriam (1998) destaca: análise documental e análise de conteúdo.

Para análise dos dados da pesquisa é realizada uma análise de conteúdo. A Análise de Conteúdo (Bardin, 1977; Bauer, 2002; Vala, 2003) também pode ser caracterizada como procedimento de fragmentação de textos com o objetivo de identificar regularidades. Possibilita tratar todo o material textual, diferentemente do Alceste, que, no corte inicial, só analisa formas reduzidas com frequência maior ou igual a 04, o que pode representar um problema por descartar sinônimos menos utilizados, identificando-os como palavras pouco frequentes.

A pesquisa documental se caracteriza pela pesquisa "[...] de materiais que não receberam ainda um tratamento analítico, ou que ainda podem ser reelaborados de acordo com os objetos da pesquisa" (Gil, 2008).

\section{Resultados e Discussão}

Para analisar como os indicadores de sustentabilidade podem auxiliar os produtores rurais a promover melhorias nos processos de gestão e desempenho de modo a torna-las mais sustentáveis, foi aplicado um checklist, considerando as duas atividades produtivas, geradoras de rendas para a propriedade rural estudada.

Nesse sentido foram investigadas individualmente cada uma das atividades e também a propriedade como um todo, utilizando-se para tanto, o modelo MASPPR (modelo para avaliar a sustentabilidade de pequenas propriedades rurais) de Vian (2020). Nesse sentido, buscou-se capturar a utilização ou não, de um conjunto de indicadores proposto pelo modelo considerando as três dimensões da sustentabilidade (econômica, social e ambiental).

Sendo assim inicialmente, foram observados os grupos de critérios que fazem parte da dimensão econômica, a qual é composta por seis (6) grupos de critérios. Nesse sentido no Quadro 1, foram apresentados os indicadores observados para cada grupo de critério que compõe a dimensão econômica.

O primeiro grupo de critérios da dimensão econômica é a Rentabilidade / Lucratividade, para o qual, são considerados quatro (4) indicadores de sustentabilidade, sendo eles Lucro Bruto, Receita Bruta, Lucro Líquido e Renda per capita, os quais compõe a dimensão econômica, visando compreender se a organização tem implementado cada indicador e como ele é percebido dentro da organização.

Com isso, para o lucro bruto, que é o primeiro indicador observado para o grupo de critérios, Rentabilidade / Lucratividade. Constatou-se que ele é calculado para as duas atividades econômicas (produção de leite e agricultura). Sendo que o gestor da propriedade, encontra esse indicador, depois de somar todos os custos de produção e os impostos, diminuindo do total de receitas brutas.

O segundo indicador que faz parte do grupo de critérios, Rentabilidade / Lucratividade é a receita bruta. Tal informação é obtida a partir da venda dos produtos, sendo que para o leite são produzidos e vendidos 15.000 litros/meses ao preço de venda de $R \$ 1,92, \log$ o o valor das receitas brutas representa 38.400,00 ao mês e 460.800,00 ao ano. A outra atividade econômica da propriedade rural é a agricultura. 
Quadro 1 - Indicadores e grupos de critérios que compõe a dimensão econômica.

\begin{tabular}{|c|c|c|c|c|c|c|c|c|c|}
\hline \multirow{2}{*}{ 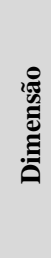 } & \multirow{2}{*}{ 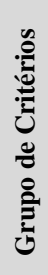 } & \multirow{2}{*}{ Critério de Sustentabilidade } & \multirow{2}{*}{ Questões } & \multicolumn{2}{|c|}{ Ambos } & \multicolumn{2}{|c|}{ Agricultura } & \multicolumn{2}{|c|}{ Leite } \\
\hline & & & & $\mathbf{S}$ & $\mathbf{N}$ & $\mathbf{S}$ & $\mathbf{N}$ & $\mathbf{S}$ & $\mathbf{N}$ \\
\hline \multirow{14}{*}{ 导 } & & Lucro Bruto & $\begin{array}{l}\mathrm{O} \mathrm{Sr}(\mathrm{a}) \text { calcula o lucro bruto da } \\
\text { propriedade, que pode ser obtido } \\
\text { retirando-se os custos da receita total? }\end{array}$ & $X$ & & $\mathrm{X}$ & & $\mathrm{X}$ & \\
\hline & : & Receita Bruta & $\begin{array}{l}\text { O Sr (a) calcula a receita bruta da } \\
\text { propriedade, a qual pode ser obtida pela } \\
\text { multiplicação do preço de venda pela } \\
\text { quantidade produzida? }\end{array}$ & X & & $\mathrm{X}$ & & $\mathrm{X}$ & \\
\hline & 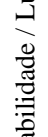 & Lucro Líquido & $\begin{array}{c}\text { O Sr (a) calcula o lucro líquido da } \\
\text { propriedade, o qual pode ser calculado } \\
\text { retirando-se todos os custos e despesas da } \\
\text { receita total? }\end{array}$ & $\mathrm{X}$ & & $\mathrm{X}$ & & $\mathrm{X}$ & \\
\hline & 莺 & Renda per capita & $\begin{array}{l}\text { O Sr (a) calcula a renda per capita na } \\
\text { propriedade, a qual compreende o total de } \\
\text { rendimentos por pessoa, podendo ser de } \\
\text { atividades agrícolas e não agrícolas, } \\
\text { possibilitando a diversificação de renda? }\end{array}$ & & $\mathrm{X}$ & & $\mathrm{X}$ & & $\mathrm{X}$ \\
\hline & 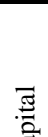 & Produtividade no Trabalho & $\begin{array}{l}\text { O Sr (a) calcula a produtividade no } \\
\text { trabalho na propriedade, ou seja, o lucro } \\
\text { criado por unidade de trabalho, em } \\
\text { determinado período? }\end{array}$ & & X & & $X$ & & $\mathrm{X}$ \\
\hline & 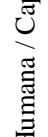 & Tipo de Mão de Obra & $\begin{array}{l}\text { Referente o tipo de mão de obra, ou seja, } \\
\text { o capital de trabalho, o Sr. (a) possui } \\
\text { disponibilidade de mão de obra familiar } \\
\text { na propriedade? }\end{array}$ & $\mathrm{X}$ & & $\mathrm{X}$ & & $\mathrm{X}$ & \\
\hline & 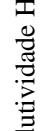 & Regime de Trabalho & $\begin{array}{l}\text { Referente ao regime de trabalho, todos os } \\
\text { colaboradores trabalham em tempo } \\
\text { integral? Se referindo ao tempo } \\
\text { disponível na propriedade. }\end{array}$ & $X$ & & & & & \\
\hline & : & Produtividade da Terra & $\begin{array}{l}\text { Referente à produtividade da terra, o Sr. } \\
\text { (a) considera a propriedade rentável, por } \\
\text { área e unidade produtiva, em termos de } \\
\text { quantidade ou qualidade? }\end{array}$ & $X$ & & $\mathrm{X}$ & & & \\
\hline & \multirow{4}{*}{ 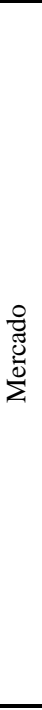 } & Cadeia de Valor & $\begin{array}{c}\text { Se referindo à possibilidade de } \\
\text { participação, inclusão, concorrência, o } \\
\text { que poderá influenciar a entrada de novos } \\
\text { participantes, como: características de } \\
\text { mercado, custos e dificuldades de } \\
\text { cumprimento e exigências da legislação, } \\
\text { o Sr (a) considera-se incluso na cadeia de } \\
\text { valor? }\end{array}$ & $X$ & & $\mathrm{X}$ & & $\mathrm{X}$ & \\
\hline & & Preço de Mercado & $\begin{array}{l}\text { O Sr (a) mantém-se informado sobre o } \\
\text { preçopraticado no mercado, o qual pode } \\
\text { auxiliar na compra e venda, aumentando } \\
\text { o poder de negociação? }\end{array}$ & $X$ & & $\mathrm{X}$ & & $\mathrm{X}$ & \\
\hline & & Diversidade de Mercado & $\begin{array}{l}\text { Referente à diversidade de mercado, o Sr. } \\
\text { (a) considera ter diversidade de opções de } \\
\text { fornecedores e clientes? }\end{array}$ & & $\mathrm{X}$ & & $\mathrm{X}$ & & $\mathrm{X}$ \\
\hline & & $\begin{array}{c}\text { Eficiência ou Disponibilidade de } \\
\text { Mercado }\end{array}$ & $\begin{array}{c}\text { Referente à eficiência ou disponibilidade } \\
\text { de mercado, o Sr. (a) considera ter } \\
\text { demanda da produção na propriedade? }\end{array}$ & $X$ & & $\mathrm{X}$ & & $\mathrm{X}$ & \\
\hline & \multirow{2}{*}{ 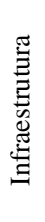 } & Imobilizado & $\begin{array}{l}\text { Sr. (a) possui na propriedade máquinas e } \\
\text { estrutura para atender as atividades? }\end{array}$ & $X$ & & $\mathrm{X}$ & & $\mathrm{X}$ & \\
\hline & & Tamanho da Propriedade & $\begin{array}{l}\text { O Sr. (a) considera que sua propriedade } \\
\text { possui tamanho suficiente para atender as } \\
\text { rápidas mudanças, como, cenário } \\
\text { econômico, regulamentações e clima? }\end{array}$ & $X$ & & $\mathrm{X}$ & & $\mathrm{X}$ & \\
\hline
\end{tabular}




\begin{tabular}{|c|c|c|c|c|c|c|c|c|}
\hline & Praticidade de Acesso & $\begin{array}{l}\text { O Sr. (a) considera que a propriedade tem } \\
\text { praticidade de acesso? Como, } \\
\text { deslocamento ou distância acessível à } \\
\text { escola, mercado, hospital e asfalto? }\end{array}$ & $X$ & & $X$ & & $X$ & \\
\hline \multirow{4}{*}{ 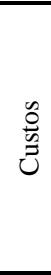 } & Custo Fixo & $\begin{array}{l}\mathrm{O} \mathrm{Sr}(\mathrm{a}) \text { calcula o custo fixo da } \\
\text { propriedade? }\end{array}$ & & $\mathrm{X}$ & & $\mathrm{X}$ & $\mathrm{X}$ & $\mathrm{X}$ \\
\hline & Custo Variável & $\begin{array}{l}\text { O Sr (a) calcula o custo variável da } \\
\text { propriedade? }\end{array}$ & & $X$ & & $X$ & $X$ & $\mathrm{X}$ \\
\hline & Custo Direto & $\begin{array}{l}\text { O Sr (a) calcula o custo direto da } \\
\text { propriedade? }\end{array}$ & & $X$ & & $\mathrm{X}$ & $X$ & $\mathrm{X}$ \\
\hline & Custo Indireto & $\begin{array}{l}\text { O Sr (a) calcula o custo indireto da } \\
\text { propriedade? }\end{array}$ & & $X$ & & $\mathrm{X}$ & $X$ & $\mathrm{X}$ \\
\hline \multirow{3}{*}{ 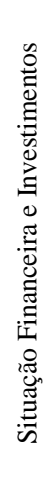 } & Fluxo de Caixa & $\begin{array}{l}\text { O Sr (a) calcula o fluxo de caixa da } \\
\text { propriedade, o qual permite verificar se } \\
\text { há possibilidade em arcar com as } \\
\text { despesas dentro do prazo estipulado, não } \\
\text { ficando sem recursos financeiros? }\end{array}$ & & $X$ & & $X$ & & $\mathrm{X}$ \\
\hline & Valor Presente Líquido - VPL & $\begin{array}{c}\text { O Sr (a) calcula o Valor Presente Líquido } \\
\text { - VPL da propriedade, o qual reflete a } \\
\text { soma dos fluxos de caixa futuros } \\
\text { descontados, incorridos no período } \\
\text { analisado? } \\
\end{array}$ & & $X$ & & $X$ & & $\mathrm{X}$ \\
\hline & Empréstimos Financiamentos & $\begin{array}{c}\text { Referente aos empréstimos financeiros e } \\
\text { o grau de endividamento na propriedade, } \\
\text { o Sr. (a) necessita de empréstimos } \\
\text { financeiros? }\end{array}$ & $X$ & & $\mathrm{X}$ & & $X$ & \\
\hline
\end{tabular}

Fonte: Elaborado pelos autores. (2021)

Ao ano são colhidos em média 700 sacas de Soja ao ano, com preço de venda de R \$160,00, representando R\$ 112.000,00 por safra anual. Para o milho são produzidas em média 1050 saca em 7 hectares, gerando 94.500,00. Assim as receitas totais da propriedade são em média de $\mathrm{R} \$ 667.300,00$ ao ano.

O lucro líquido, que também integra o grupo de critérios, Rentabilidade / Lucratividade, é obtido ao deduzir do lucro bruto as demais despesas, necessária a execução das atividades administrativas, vendas e financeiras., calculado para as duas atividades econômicas (produção de leite e agricultura) e representa em média 23\% da receita bruta anual.

A renda per capta, que é a renda por pessoa, em que pode ser as geradas pelas atividades agrícolas e não agrícolas e que possibilita a diversificação de renda, não é calculada na propriedade. Considerando a literatura sobre o tema, esse indicador esconde muitas diferenças sobre a distribuição da renda (Pereira \& Stülp, 2019). Um país, por exemplo, pode até ter uma renda per capita alta, mas pode ter um alto índice de concentração de renda, o que de acordo com Pereira e Stülp (2019), escancaram grandes desigualdades sociais. Também é possível um país tenha uma baixa renda per capita e não tenha grande concentração de renda, o que denota não existir grandes desigualdades sociais. Sendo assim apesar de ser um indicador bastante usual e que traz percepções importantes acerca da renda média individual, destaca-se a importância de se ter cuidados ao considerar o contexto.

Com isso, por ser um indicador de sustentabilidade, que mostra o quanto de renda por pessoa é produzido na propriedade, facilitando a compreensão de quanto de recursos é gerado para os gastos individuais de cada membro familiar. Sendo assim, neste estudo, por ser um indicador que representa a renda correspondente a cada um dos integrantes da família, que trabalha na propriedade, é relevante indicar aos gestores a sua utilização para fins de análise.

Dentro da dimensão econômica o segundo grupo de critérios observado foi a Produtividade Humana / Capital, para o qual são observados quatro (4) indicadores: Produtividade no Trabalho, Tipo de Mão de Obra, Regime de Trabalho e Produtividade da Terra. Inicialmente buscou-se saber se existe implementado na propriedade o acompanhamento da produtividade no trabalho, o qual busca saber se é calculado o lucro criado por unidade de trabalho, em um determinado período. A unidade de trabalho refere-se ao trabalhador/pessoa que desempenha as atividades que são relacionadas as atividades rurais da propriedade investigada. 
Para a situação em questão, destaca-se que para a atividade leiteira as fazes da produção vão desde a inseminação, alimentação e a nutrição, saúde e bem-estar animal, ordenha e armazenamento para a expedição do leite. A atividade agrícola para a soja e o milho, que são as culturas produzidas nesta propriedade, as etapas de produção e vendas vão desde o preparo da terra, plantio, colheita e expedição para vendas.

Para o caso analisado este é um indicador que não é calculado pelo gestor da propriedade. No entanto, por indicar a produtividade no trabalho na propriedade, ou seja, de acordo com Vian (2020) refere-se ao lucro criado por unidade de trabalho, em determinado período, entende-se como sendo um indicador útil para melhorar os níveis de sustentabilidade na organização.

O segundo indicador observado no segundo grupo de critérios que indica a sustentabilidade da propriedade rural é o Tipo de mão de obra, o qual de acordo com Vian (2020), é o capital de trabalho, buscando-se saber se é utilizada a mão de obra familiar na propriedade. Denota-se que este indicador é percebido na organização objeto de estudo, visto que trabalham na propriedade, 3 das 4 pessoas que compõe o grupo familiar, sendo que uma das pessoas não trabalha em razão da idade ser avançada.

O terceiro indicador que compõe o segundo grupo de critérios da dimensão econômica trata do regime de trabalho, sendo que para Vian (2020), é procurar saber se todos os colaboradores trabalham em tempo integral, na propriedade, o que é percebido na propriedade investigada, sendo que as 3 pessoas que compõe o grupo familiar e que trabalham, atuam integramente na propriedade.

O terceiro indicador para este grupo de critérios é a produtividade da terra que segundo Vian (2020), busca saber se a propriedade é rentável, por área e unidade produtiva, em termos de quantidade ou qualidade da produção. Este indicador é percebido na propriedade para ambas as atividades.

O terceiro grupo de critérios que compõe a dimensão econômica é o Mercado e neste grupo são analisados quatro indicadores (4): a cadeia de valor; o preço de mercado, a diversidade de mercado e a eficiência e disponibilidade de mercado. O primeiro indicador que se refere a cadeia de valor, observa a possibilidade de participação, inclusão, concorrência (Oliveira \& Costa, 2017), buscando entender o que pode influenciar a entrada de novos participantes, se são as características de mercado, os custos, as dificuldades de cumprimento e exigências da legislação. Nesse sentido, de acordo com o respondente para as atividades econômicas da propriedade ele considera-se incluso na cadeia de valor.

O segundo indicador deste grupo é o preço de mercado que segundo Nunes (2018), trata do preço praticado no mercado, para os produtos produzidos na propriedade. Para identificar se este indicador está presente na organização de estudo, foi perguntado se o proprietário/gestor da propriedade se mantém informado sobre isso, uma vez que este pode auxiliar na compra e venda, aumentando o poder de negociação. Neste sentido, a partir do que fora indicado pelo respondente ele está sempre atento aos preços de mercados dos produtos que produz e vende.

O terceiro indicador é a Diversidade de Mercado, que Vian (2020), menciona se tratar da propriedade possuir diversidade de opções de fornecedores e clientes. Neste sentido observa-se que apesar de existirem diversas opções de fornecedores e compradores o gestor tem optado por manter transações econômicas focadas na cooperativa da qual é cooperado para os grãos, assim como para o leite tem uma parceria com um comprador a um longo tempo. Com isso sugere-se a partir do indicado por Vian (2020), a diversificação de fornecedores e clientes, para evitar a dependência de um ou poucos fornecedores ou clientes.

Para finalizar este grupo de critérios que analisa a interação do objeto de análise com o mercado, foi observado a Eficiência ou Disponibilidade de Mercado Referente, que busca saber se existe demanda da produção da propriedade (Vian, 2020). Para este indicador o entrevistado menciona existir demandas para a produção das duas atividades.

O quarto grupo de critérios da dimensão economia á a Infraestrutura. Este indicador contempla três (3) indicadores, 
que observam a estrutura do imobilizado, o tamanho da propriedade e a praticidade de acesso.

Com isso o primeiro indicador observado neste grupo de critério foi o imobilizado que de acordo com Iudicibus, et al. (2010), o ativo imobilizado é composto pelos ativos tangíveis ou os que são corpóreos de permanência duradoura, que são destinados ao funcionamento normal da sociedade e de seu empreendimento, como também os direitos que são exercidos com essa finalidade.

Quanto ao tamanho da propriedade, segundo Vian (2020) este indicativo verifica se propriedade possui tamanho suficiente para atender as rápidas mudanças, como, cenário econômico, regulamentações e clima. Sendo assim o respondente destaca que tem buscado se preparar para possíveis mudanças, sejam climáticas ou de mercado, assim como está atento às regulamentações. Pois o mercado é muito competitivo, e exige constantes melhorias.

O terceiro indicador do grupo de critérios infraestrutura refere-se à praticidade de acesso, que Vian (2020), menciona considerar se a propriedade tem praticidade de acesso, de deslocamento ou distância acessível à escola, mercado, hospital e asfalto. Nota-se, a partir da resposta do gestor que a propriedade é localizada perto do asfalto, e isso facilita muito para os leiteiros que buscam o leite até a casa do produtor, e isso chama a atenção dos fornecedores por conta de ser de fácil acesso.

O quinto grupo de critérios da dimensão economia são os custos. Neste contexto os indicadores que compõe este grupo de critérios são os Custos fixos, variáveis, diretos e indiretos. Para estes indicadores apesar de relevantes para a gestão (Martins, 1999) conhecê-los de forma separada, na organização estudada o gestor tem a informação da soma dos custos, mas não classifica em custos fixos, variáveis, diretos e indiretos de forma separada. Sendo assim, sugere-se esta separação, o que possibilita acompanhar e corrigir possíveis distorções.

Por fim o sexto e último grupo de critérios que o modelo (Vian, 2020) sugere para identificar a sustentabilidade da dimensão econômica é o grupo que trata da Situação Financeira e Investimentos, sendo que os indicadores tratados aqui são: o fluxo de caixa, o valor presente líquido - VPL e empréstimos financeiros.

Nota-se que o primeiro indicador pertencente a este grupo de critérios que são o fluxo de caixa, o qual permite verificar se há possibilidade em arcar com o pagamento de gastos dentro do prazo estipulado, não ficando sem recursos financeiros. Constatou-se que a propriedade não pois ele estruturado, o gestor, sempre que precisa dessa informação, ele faz o levantamento do que tem pra receber e pagar.

O mesmo acontece com o valor presente líquido - VPL dos investimentos realizados na propriedade, o qual reflete a soma dos fluxos de caixa futuros descontados, incorridos no período analisado, o gestou não calcula e nem sabe como fazer. Nesse sentido dada a importância destes dois indicadores para a gestão da organização, sugere-se que o gestor da propriedade utilize uma estrutura para organizar e acompanhar o seu fluxo de caixa periódico, assim como o valor presente líquido do fluxo de caixa como previsto por (Santos et al., 2009).

Por fim ao observar o indicador empréstimos financeiros, que segundo Vian (2020), refere-se aos empréstimos financeiros e o grau de endividamento na propriedade, nota-se que é utilizado para realizar compras para a propriedade, como insumos que é utilizado para a lavoura, para a compra de vacas e máquinas e equipamentos.

Dos 22 indicadores de sustentabilidade econômica, proposto pelo modelo de Vian (2020), foram identificados 13, representando 59,09\% dos indicadores dimensão, o que indica que a sustentabilidade econômica ficou em torno de $60 \%$. No entanto ao atribuir o mesmo peso a esta dimensão em comparação com as demais (social e ambiental) (Elkington, 1997), esta representatividade representa $19,70 \%$.

Para a dimensão social, foram observados sete (7) grupos de critérios pertencentes a essa dimensão, bem como vinte e dois (22) indicadores sociais pertencentes aos grupos de critérios dessa dimensão. Com isso, no Quadro 2, foram apresentados os indicadores observados para cada grupo de critério que compõe a dimensão social.

O primeiro grupo de critérios da dimensão social, observado foi a Saúde e Segurança Humana. Para este grupo foram 
considerados três (3) indicadores sociais que são: risco a saúde, acidente de trabalho e qualidade de vida. O primeiro indicador social deste grupo de critério foi o risco a saúde que de acordo com Vian (2020), diz respeito às condições e práticas de trabalho: como, barulho, vibrações, estresse, utilização de produtos químicos, agrotóxicos e contato com substâncias perigosas, sendo que para tanto buscou-se saber se as condições de trabalho na propriedade são adequadas à saúde.

No segundo indicado é observado a prevenção a acidente de trabalho na propriedade, ao se referir ao uso de equipamentos de proteção, prevenção para carga física e operações repetitivas. Nota-se para estes dois indicadores, a partir das respostas do gestor que a propriedade não utiliza equipamentos que melhoram a segurança, apenas máscaras que são utilizadas para proteger da poeira

Quanto ao terceiro indicador que é a qualidade de vida, o qual para Vian (2020), se refere a presença da qualidade do ambiente, fontes de água e ar, que proporcionam bem-estar, indicando que há qualidade de vida na propriedade. Observa-se a partir das respostas dadas pelo respondente, haver uma boa qualidade do ambiente da propriedade, com fontes de água e ar que proporcionam bem-estar.

O segundo grupo de critérios é a segurança alimentar, sendo este grupo composto por dois (2) indicadores sociais, que são as refeições diárias e qualidade dos alimentos. Quanto as refeições diárias, busca-se saber se existem refeições diárias suficientes, equilibradas e diversificadas na propriedade. Nesse sentido verificou-se haver refeições suficientes, com um cardápio rico em proteína e saudável, desde o café da manhã, para o almoço, lanches entre as refeições e janta leve para prejudicar o sono.

Quanto ao segundo indicador que trata da qualidade dos alimentos, Vian (2020), destaca a qualidade dos alimentos na propriedade é observação quando os produtos são de qualidade, livre de contaminação para consumir e oferecer, o que de acordo com o gestor existe na propriedade.

Quadro 2 - Indicadores e grupos de critérios que compõe a dimensão social.

\begin{tabular}{|c|c|c|c|c|c|c|c|c|c|}
\hline \multirow{2}{*}{ 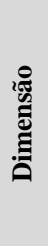 } & \multirow{2}{*}{ 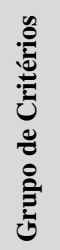 } & \multirow{2}{*}{$\begin{array}{c}\text { Critério de } \\
\text { Sustentabilidade }\end{array}$} & \multirow{2}{*}{ Questões } & \multicolumn{2}{|c|}{ Ambos } & \multicolumn{2}{|c|}{ Agricultura } & \multicolumn{2}{|c|}{ Leite } \\
\hline & & & & $\mathbf{S}$ & $\mathbf{N}$ & $\mathbf{S}$ & $\mathbf{N}$ & $\mathbf{S}$ & $\mathbf{N}$ \\
\hline \multirow{5}{*}{ ¿্য } & \multirow{3}{*}{ 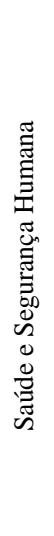 } & Risco a Saúde & $\begin{array}{c}\text { Ao se reportar as condições e práticas de } \\
\text { trabalho: como, barulho, vibrações, } \\
\text { estresse, utilização de produtos químicos, } \\
\text { agrotóxicos e contato com substâncias } \\
\text { perigosas, o } \mathrm{Sr} \text { (a) considera as condições } \\
\text { de trabalho na propriedade adequadas à } \\
\text { saúde? }\end{array}$ & & $\mathrm{X}$ & & $\mathrm{X}$ & & $\mathrm{X}$ \\
\hline & & Acidente de Trabalho & $\begin{array}{l}\text { Se referindo ao uso de equipamentos de } \\
\text { proteção, prevenção para carga física e } \\
\text { operações repetitivas, há prevenção contra } \\
\text { acidentes de trabalho na propriedade? }\end{array}$ & & $\mathrm{X}$ & & $\mathrm{X}$ & & $\mathrm{X}$ \\
\hline & & Qualidade de Vida & $\begin{array}{l}\text { Se referindo a qualidade do ambiente, } \\
\text { fontes de água e ar, que proporcionam } \\
\text { bem-estar, há qualidade de vida na } \\
\text { propriedade? }\end{array}$ & $\mathrm{X}$ & & $X$ & & X & \\
\hline & \multirow{2}{*}{ 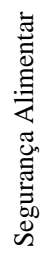 } & Refeições Diárias & $\begin{array}{l}\text { Há refeições diárias suficientes, } \\
\text { equilibradas e diversificadas na } \\
\text { propriedade? }\end{array}$ & $\mathrm{X}$ & & $\mathrm{X}$ & & $X$ & \\
\hline & & $\begin{array}{l}\text { Qualidade dos } \\
\text { Alimentos }\end{array}$ & $\begin{array}{l}\text { Se referindo aos produtos de qualidade, } \\
\text { livre de contaminação para consumir e } \\
\text { oferecer, há qualidade dos alimentos na } \\
\text { propriedade? }\end{array}$ & $\mathrm{X}$ & & $\mathrm{X}$ & & $X$ & \\
\hline
\end{tabular}




\begin{tabular}{|c|c|c|c|c|c|c|c|c|}
\hline \multirow{4}{*}{ 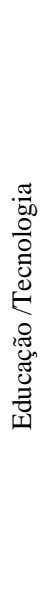 } & Nível de Educação & $\begin{array}{l}\text { Se referindo ao nível de escolaridade, } \\
\text { formação agrícola, frequência escolar, há } \\
\text { nível de educação na propriedade? }\end{array}$ & $\mathrm{X}$ & & $\mathrm{X}$ & & $\mathrm{X}$ & \\
\hline & Nível de Experiência & $\begin{array}{l}\text { Se referindo à aprendizagem adquirida ao } \\
\text { longo da vida, o conhecimento das } \\
\text { melhores práticas de gestão e produção, há } \\
\text { nível de experiência na propriedade? }\end{array}$ & $\mathrm{X}$ & & $\mathrm{X}$ & & $\mathrm{X}$ & \\
\hline & Uso de Tecnologia & $\begin{array}{l}\text { Se referindo ao nível de maquinários e } \\
\text { investimentos, uso de recursos } \\
\text { tecnológicos, acesso à média eletrônica e } \\
\text { internet, há uso de tecnologias na } \\
\text { propriedade? }\end{array}$ & & $\mathrm{X}$ & & $\mathrm{X}$ & & $\mathrm{X}$ \\
\hline & Treinamento Agrícola & $\begin{array}{l}\text { Relativo às reuniões de treinamento, as } \\
\text { atualizações contínuas, troca de práticas e } \\
\text { conhecimentos entre os agricultores, há } \\
\text { treinamento agrícola na propriedade? }\end{array}$ & $\mathrm{X}$ & & $\mathrm{X}$ & & $\mathrm{X}$ & \\
\hline \multirow{3}{*}{ 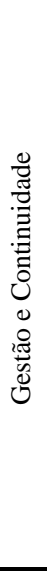 } & Idade/Continuidade & $\begin{array}{l}\text { Referente à idade/continuidade, que é } \\
\text { relativa à composição, por exemplo, de } \\
\text { jovens e idosos, as mudanças } \\
\text { demográficas, e a perspetiva de } \\
\text { continuidade ou risco de abandono da área } \\
\text { rural, o Sr. (a) acredita que há boas } \\
\text { perspetivas de sucessão na propriedade? }\end{array}$ & & $\mathrm{X}$ & & $X$ & & $\mathrm{X}$ \\
\hline & Estratégia de Gestão & $\begin{array}{l}\text { Se referindo ao planejamento estratégico, } \\
\text { ao desempenho, a capacidade de } \\
\text { adaptação, melhorias de práticas e } \\
\text { autonomia na tomada de decisão, há } \\
\text { estratégias de gestão na propriedade? }\end{array}$ & & $\mathrm{X}$ & & $\mathrm{X}$ & & $\mathrm{X}$ \\
\hline & Controle da Gestão & $\begin{array}{l}\text { Se referindo à composição da liderança, } \\
\text { comunicação interna, sistemas de controle } \\
\text { interno, registros, solução de conflitos, o } \\
\text { cumprimento a legislação, há controle da } \\
\text { gestão na propriedade? }\end{array}$ & & $\mathrm{X}$ & & $\mathrm{X}$ & & $\mathrm{X}$ \\
\hline \multirow{2}{*}{ 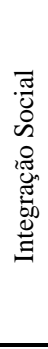 } & Apoio da Comunidade & $\begin{array}{l}\text { Se referindo ao apoio a períodos de } \\
\text { dificuldade da família, como: doença, } \\
\text { morte e desastres naturais, há apoio da } \\
\text { comunidade? }\end{array}$ & & $\mathrm{X}$ & & $\mathrm{X}$ & & $\mathrm{X}$ \\
\hline & Envolvimento Social & $\begin{array}{l}\text { Se referindo a participação nas atividades } \\
\text { recreativas e culturais, envolvimento em } \\
\text { atividades coletivas, capacidade de } \\
\text { trabalho em equipe, vínculo cultural e } \\
\text { histórico com as comunidades locais, há } \\
\text { envolvimento social da propriedade? }\end{array}$ & & $\mathrm{X}$ & & $\mathrm{X}$ & & $\mathrm{X}$ \\
\hline \multirow{5}{*}{ 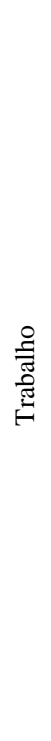 } & Oportunidade Trabalho & $\begin{array}{l}\text { Se referindo à criação e quantidade de } \\
\text { empregos gerados, o Sr. (a) acredita que a } \\
\text { oportunidade de trabalho na propriedade? }\end{array}$ & $X$ & & $X$ & & $\mathrm{X}$ & \\
\hline & Condição de Trabalho & $\begin{array}{l}\text { Se referindo ao ambiente, características e } \\
\text { a qualidade de trabalho, como: direitos } \\
\text { trabalhistas, tempo e carga de trabalho, } \\
\text { acesso a maquinários, tecnologias e } \\
\text { práticas adequadas, há condições de } \\
\text { trabalho na propriedade? } \\
\end{array}$ & & $\mathrm{X}$ & & $\mathrm{X}$ & & $\mathrm{X}$ \\
\hline & Renda e Padrão de Vida & $\begin{array}{c}\text { Se referindo ao salário suficiente para } \\
\text { possibilitar um padrão de vida aceitável, } \\
\text { salário justo, há renda e padrão de vida na } \\
\text { propriedade? }\end{array}$ & $\mathrm{X}$ & & $\mathrm{X}$ & & $\mathrm{X}$ & \\
\hline & $\begin{array}{c}\text { Força de Trabalho } \\
\text { Agrícola }\end{array}$ & $\begin{array}{l}\text { Se referindo ao trabalho familiar, trabalho } \\
\text { total e por gênero, há força de trabalho } \\
\text { agrícola na propriedade? }\end{array}$ & $\mathrm{X}$ & & $\mathrm{X}$ & & $\mathrm{X}$ & \\
\hline & $\begin{array}{l}\text { Oportunidade de } \\
\text { Trabalho }\end{array}$ & $\begin{array}{l}\text { Se referindo à criação e quantidade de } \\
\text { empregos gerados, o Sr. (a) acredita que a } \\
\text { oportunidade de trabalho na propriedade? }\end{array}$ & $\mathrm{X}$ & & $\mathrm{X}$ & & $\mathrm{X}$ & \\
\hline
\end{tabular}




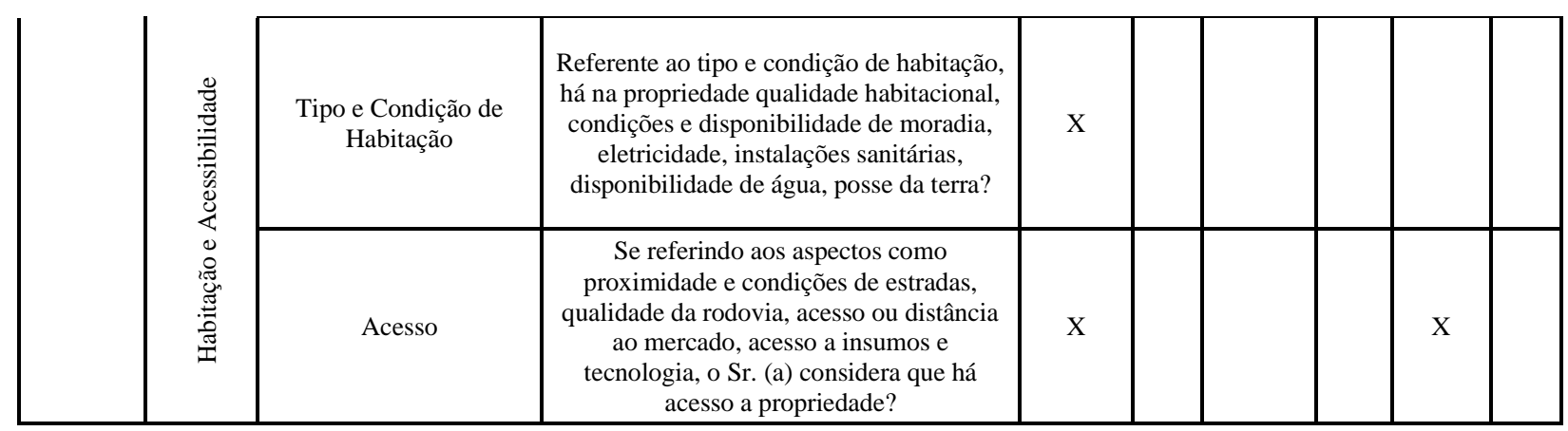

Fonte: Elaborado pelos autores (2021).

No terceiro grupo de critérios, o qual trata de Educação /Tecnologia, é formado por quatro (4) indicadores sociais, que são educação, experiência, uso de tecnologia e treinamento agrícola.

A educação, que se refere ao nível de escolaridade, formação agrícola, frequência escolar, na propriedade, como proposto por Vian (2020), está presente na propriedade em parte. Nota-se a partir da resposta do gestor que ele e a esposa estudaram até a $5^{\mathrm{a}}$ série do ensino fundamental, pelo fato de que na época, as pessoas precisavam trabalhar na roça e não conseguiam estudar, no entanto, eles possuem cursos de formação livre relacionados as atividades da propriedade, o qual é oferecido pela cooperativa que eles são cooperados e grande experiencia em razão do tempo de atuação na área. Também o filho do casal que também trabalha na propriedade está concluindo o ensino superior. Tais constatação indicam a presença deste indicador na propriedade estudada.

O indicador experiência, que segundo Vian (2020), se refere à aprendizagem adquirida ao longo da vida, o conhecimento das melhores práticas de gestão e produção, que como mencionado o prioritário tem grande experiência e faz treinamentos. Portanto, a partir do que fora mencionado pelo respondente, existe experiência na propriedade.

Para o indicador uso de tecnologia, o qual trata dos maquinários e investimentos, uso de recursos tecnológicos, acesso à mídia eletrônica e internet, há uso de tecnologias na propriedade. Nota-se que este indicador não está presente na propriedade, visto que as máquinas utilizadas não têm tecnologia avançada e também os trabalhadores só usam a internet e mídias eletrônicas em caso de precisar de alguma informação que precise buscar na rede.

Por fim o treinamento agrícola, que de acordo com Vian (2020), se refere às reuniões de treinamento, as atualizações contínuas, troca de práticas e conhecimentos entre os agricultores, nota-se, a partir das respostas, que existem treinamentos relacionados as atividades econômicas da propriedade, uma vez que o proprietário participa de reuniões com produtores e cooperados que produzem leite e grãos, assim como realiza treinamentos sobre o tema.

O quarto grupo de critérios é a gestão e continuidade, este critério é composto por três (3) indicadores que são idade/continuidade, estratégia de gestão e controle da gestão.

Quanto a idade/continuidade, que segundo Vian (2020), é relativo à composição, de jovens e idosos, as mudanças demográficas, e a perspectiva de continuidade ou risco de abandono da área rural, o respondente afirma não existir perspectivas de sucessão na propriedade. O gestor tem filhos, mas que não pretendem dar continuidade ao trabalho na propriedade, ambos entendem que mesmo o ramo agrícola e de leite dar um bom retorno, eles entendem demandar de grande envolvimento diário com as atividades econômicas, implicando em sacrificar férias e descanso. Além da necessidade de manter-se permanentemente atualizado. Com isso o proprietário não está confiante de que seus filhos continuem o negócio, pelo fato de ser um serviço que exige muito das pessoas, por não ter finais de semana ou feriados, sempre precisa estar ali para resolver o que tiver que fazer.

O segundo indicador é a estratégia de gestão, que trata do planejamento estratégico, do desempenho, capacidade de adaptação, das melhorias de práticas e autonomia na tomada de decisão. Nesse sentido o gestor/proprietário, destaca que possui 
estratégia de gestão, estabelece metas a serem atingidas, visando o crescimento e manutenção ou melhoria do desempenho, com isso tem focado no bem-estar do animal para que produza mais leite, em conhecer novas práticas de cultivo, para melhorar a qualidade e produtividade do grão.

Nota-se, no entanto ao questionar sobre a formalização do planejamento que este não é discutido com os outros membros e não foi declarado no papel, logo não há estratégia de gestão na propriedade. Além disso se restringem ao desempenho econômico, não tem foco na segurança, qualidade de vida, bem-estar das pessoas, o que poderia mudar a visão dos filhos sobre o negócio e fazer com que eles permaneçam na atividade.

Por fim, quanto ao indicador de controle da gestão, Vian (2020), menciona tratar da composição da liderança, da comunicação interna, dos sistemas de controle interno, registros, solução de conflitos, do cumprimento a legislação, nota-se a partir da investigação que existe liderança a partir do pai, que é o gestor e determina todo o andamento das atividades e também busca atender as exigências legais. No entanto não existe registro formalizado dos procedimentos, assim como os conflitos não são discutidos e sim aceitos pelos demais. Sendo assim percebe-se que não existe controle de gestão na propriedade.

Nesse contexto sugere-se para este grupo de critérios que trata da gestão e continuidade, maior atenção no que se refere criar e implementar alternativas que possibilitem maior qualidade de vida e bem estar aos trabalhadores, o que poderia viabilizar a vontade dos filhos em permanecer na atividade e a sucessão da propriedade, maior envolvimento de todos nas decisões e também formalização e registros do planejamento e do controle das atividades.

O quinto grupo de critérios é a integração social, o qual é composto por dois (2) indicadores que são o apoio da comunidade e o envolvimento social. O primeiro indicador é o apoio da comunidade, que trata do apoio nos períodos de dificuldade da família, como: doença, morte e desastres naturais (Vian, 2020), De acordo com o respondente, este apoio não existe. Com isso sugere-se ao gestor, buscar construí um relacionamento mais estreito com a comunidade do entorno à localização da propriedade.

O segundo indicador tratado neste grupo de critério e o envolvimento social, segundo Vian (2020), trata da participação nas atividades recreativas e culturais, do envolvimento em atividades coletivas, capacidade de trabalho em equipe, do vínculo cultural e histórico com as comunidades locais. $\mathrm{O}$ respondente menciona não ter este envolvimento social, pois não participou de nenhuma atividade recreativa ou cultural, prioriza a sua participação em eventos que envolvem bovinos e lavouras, que trazem aprendizados para aplicar na propriedade.

Carvalho, et al. (2020), destacam que os relacionamentos precisam ser cultivados, e o fato de o gestor/proprietário da organização rural não ter envolvimento social pode ser o motivo pelo qual também a comunidade não o apoia em momentos adversos.

O sexto grupo de critérios é trabalho, que é composto por cinco (5) indicadores que são; oportunidade de trabalho, condição de trabalho, renda e padrão de vida, força de trabalho agrícola e oportunidade de trabalho.

O indicador social oportunidade de trabalho, é mencionado por Vian (2020), como sendo o que trata da criação e quantidade de empregos gerados, pela propriedade. Nesse sentido o respondente destaca que "tem trabalho para quem precisa e quer trabalhar, mas é difícil encontrar quem queira realmente trabalhar. Muitas vezes o tem necessidade de contratação, mas é difícil encontrar quem tenha interesse."

Condição de trabalho, é um indicador social que segundo Vian (2020), trata do ambiente, características e da qualidade de trabalho, como: direitos trabalhistas, tempo e carga de trabalho, acesso a maquinários, tecnologias e práticas adequadas. Nota-se a partir da pesquisa que este indicador não está presente na propriedade, inicialmente por ela não ter funcionários e também em razão já ter sido observado em outros momentos do estudo que a organização não utiliza máquinas e equipamentos com tecnologias avançadas e também não são utilizados equipamentos de segurança na execução das 
atividades.

Quanto a renda e padrão de vida, nota-se que o salário/remuneração é suficiente para possibilitar um padrão de vida aceitável, salário justo, existindo renda e um bom padrão de vida na propriedade.

A força de trabalho agrícola, considera o trabalho familiar, trabalho total e por gênero, nesse sentido pode-se indicar a partir da resposta dada pelo gestor que há força de trabalho agrícola na propriedade, visto que toda a família se envolve no trabalho da propriedade, contribuindo para o crescimento.

Por fim o quinto indicador social deste grupo de critério que trata do trabalho, aborda a oportunidade de trabalho, se referindo à criação e quantidade de empregos gerados (Vian, 2020). Nesse contexto o gestor destaca que existem oportunidades de trabalho na propriedade, porem tem falta de interessados em trabalhar nestas atividades.

O sétimo grupo de critérios da dimensão social é habitação e acessibilidade, este grupo é composto por dois (2) indicadores sociais que só o tipo e condição de habitação e o acesso. O primeiro indicador social deste grupo (tipo e condição de habitação), trata do tipo e condição de habitação, há na propriedade qualidade habitacional, condições e disponibilidade de moradia, eletricidade, instalações sanitárias, disponibilidade de água, posse da terra. Nota-se a partir da perceção do respondente que as condições de habitação que envolve a moradia, água, saneamento, eletricidade e posse da terra, são adequadas ao bem-estar do proprietário e da sua família que são quem trabalha e vivem na propriedade.

O indicador social acesso, se refere, segundo Vian (2020), aos aspectos de proximidade e condições de estradas, qualidade da rodovia, acesso ou distância ao mercado, acesso a insumos e tecnologia. Observa-se com a resposta obtida, que a propriedade tem localização próxima ao asfalto, com estradas bem conservadas, que permitem ir e vir com tranquilidade e rapidez para a cidade sempre que precisar e possui acesso a internet, que auxilia na comunicação e busca de informação.

Dos 21 indicadores de sustentabilidade social, proposto pelo modelo de Vian (2020), foram identificados 12 indicadores na organização estudada, o que indica que a sustentabilidade para a dimensão social de $57,14 \%$. Destaca-se que ao considerar pesos semelhantes entre as três dimensões de sustentabilidade (econômica, social e ambiental), de acordo com o sugerido por (Elkington, 1997), esta representatividade é de 19,05\%.

Para a dimensão ambiental, foram observados seis (6) grupos de critérios pertencentes a essa dimensão, bem como dezesseis (16) indicadores ambientais pertencentes a estes grupos de critérios. Com isso, no Quadro 3, foram apresentados os indicadores observados para cada grupo de critério que compõe a dimensão ambiental.

O primeiro grupo de critérios para a dimensão ambiental é a qualidade do solo, que é composto por cinco (5) indicadores ambientais que são: a rotação das culturas, cobertura de solo, estrutura do solo, atributos químicos e risco de erosão. Sendo que o indicador rotação das culturas auxilia com ervas daninhas e controle de pragas.

Quanto a cobertura de solo na propriedade, que é um aspecto ser maximizado por elevar a taxa de infiltração e conservação da matéria orgânica. Observa-se a partir do indicado pelo respondente que existe cobertura do solo na propriedade.

O indicador estrutura do solo, de acordo com Vian (2020), se refere ao atributo físico do solo, como agregação, estrutura dos poros e densidade. Nesse sentido o gestor acredita que a estrutura do solo atende as demandas da propriedade.

Quanto aos atributos químicos Vian (2020), destaca que trata do PH do solo, que mede a acidificação, a condutividade elétrica que mede a concentração do sal, e os nutrientes como nitrogênio, fósforo, dentre outros. Nota-se, considerando a perceção do gestor que os atributos químicos atendem as demandas da propriedade.

Finalizando as observações dos indicadores ambientais para o grupo de critério que trata da qualidade do solo, foi verificado o indicador que se refere ao risco de erosão na propriedade, que pode ser devido ao excesso de preparo do solo, compactação do solo ocasionada pelas máquinas, dentre outras práticas. Nota-se de acordo com a resposta do gestor, que a propriedade é livre de risco de erosão. 
O segundo grupo de critérios é a Poluição Ambiental, que é composto por dois (2) indicadores ambientais que são: os agrotóxicos e a queima de combustíveis fósseis, desmatamento, descarte inadequado de dejetos animais.

Quanto ao indicador aagrotóxicos, busca-se verificar se a propriedade é livre de danos causados por agrotóxicos causados por agrotóxicos, como pesticidas, inseticidas, herbicidas, fungicidas e fertilizantes químicos. O gestor menciona que o meio ambiente deve ser preservado, então são tomados todos os cuidados com venenos próximos de rios e nascentes para que não envenene a água. Visto que a falta de cuidados prejudica também a saúde das pessoas e dos animais, levando inclusive a morte.

O segundo indicador trata da queima de combustíveis fósseis, desmatamento, descarte inadequado o de dejetos animais e se refere de acordo com Vian (2020), aos fatores que ocasionam poluição ambiental e mudanças climáticas devido aos gases do efeito estufa. Nota-se, a partir do estudo que a propriedade é livre da queima de combustíveis fósseis, desmatamento, descarte inadequado de dejetos animais. $\mathrm{O}$ gestor menciona que a propriedade possui lugar apropriado para o descarte dos dejetos de animais, que são os açudes aonde vai tudo o que possa prejudicar o meio ambiente.

O terceiro grupo de critérios é a biodiversidade/uso da terra, que é composto por dois (2) indicadores ambientais que são: a biodiversidade de ecossistemas, espécies e diversidade genética e a ocupação da terra e os propósitos de sua alocação.

Nesse sentido o primeiro indicador ambiental desse grupo (biodiversidade de ecossistemas, espécies e diversidade genética), se refere ao número de variedade de diferentes seres vivos, preocupação com a proteção das espécies, conservação, diversidade genética das culturas, de espécies animais e habitats naturais, áreas não cultivadas e lagoas; biodiversidade natural e agrícola (Vian, 2020). Nota-se, de acordo com o indicado pelo respondente, que existe biodiversidade de ecossistemas, espécies e diversidade genética na propriedade.

Quadro 3 - Indicadores e grupos de critérios que compõe a dimensão ambiental.

\begin{tabular}{|c|c|c|c|c|c|c|c|c|c|}
\hline \multirow{2}{*}{ 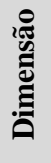 } & \multirow{2}{*}{ 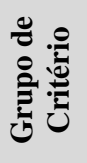 } & \multirow{2}{*}{$\begin{array}{c}\text { Critério de } \\
\text { Sustentabilidade }\end{array}$} & \multirow{2}{*}{ Questões } & \multicolumn{2}{|c|}{ Ambos } & \multicolumn{2}{|c|}{ Agricultura } & \multicolumn{2}{|c|}{ Leite } \\
\hline & & & & $\mathbf{S}$ & $\mathbf{N}$ & $\mathbf{S}$ & $\mathbf{N}$ & $\mathbf{S}$ & $\mathbf{N}$ \\
\hline \multirow{3}{*}{ 至 } & \multirow{3}{*}{ 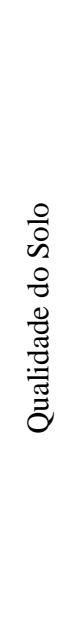 } & $\begin{array}{l}\text { Rotação das } \\
\text { culturas }\end{array}$ & $\begin{array}{l}\text { Auxiliando, por exemplo, com } \\
\text { ervas daninhas e controle de } \\
\text { pragas, é realizada rotação de } \\
\text { cultura na propriedade? }\end{array}$ & $\mathrm{X}$ & & $\mathrm{X}$ & & $\mathrm{X}$ & \\
\hline & & Cobertura de Solo & $\begin{array}{l}\text { Se referindo a cobertura do solo na } \\
\text { propriedade, que é um aspecto a ser } \\
\text { maximizado por elevar a taxa de } \\
\text { infiltração e conservação da } \\
\text { matéria orgânica, há cobertura do } \\
\text { solo na propriedade? }\end{array}$ & $\mathrm{X}$ & & $\mathrm{X}$ & & $\mathrm{X}$ & \\
\hline & & Estrutura do Solo & $\begin{array}{l}\text { Se referindo ao atributo físico do } \\
\text { solo, como agregação, estrutura dos } \\
\text { poros e densidade, o Sr. (a) acredita } \\
\text { que a estrutura do solo atende as } \\
\text { demandas da propriedade? }\end{array}$ & $\mathrm{X}$ & & $\mathrm{X}$ & & $\mathrm{X}$ & \\
\hline
\end{tabular}




\begin{tabular}{|c|c|c|c|c|c|}
\hline & $\begin{array}{l}\text { Atributos } \\
\text { Químicos }\end{array}$ & $\begin{array}{l}\text { Se referindo aos atributos } \\
\text { químicos, como o PH que mede a } \\
\text { acidificação, a condutividade } \\
\text { elétrica que mede a concentração } \\
\text { do sal, e os nutrientes como } \\
\text { nitrogênio, fósforo, dentre outros, o } \\
\text { Sr. (a) acredita que os atributos } \\
\text { químicos atendem as demandas da } \\
\text { propriedade? }\end{array}$ & $X$ & $X$ & $\mathrm{X}$ \\
\hline & Risco de Erosão & $\begin{array}{c}\text { Se referindo ao risco de erosão na } \\
\text { propriedade, que pode ser devido } \\
\text { ao excesso de preparo do solo, } \\
\text { compactação do solo ocasionada } \\
\text { pelas máquinas, dentre outras } \\
\text { práticas, o Sr. (a) acredita que a } \\
\text { propriedade é livre de risco de } \\
\text { erosão? }\end{array}$ & $\mathrm{X}$ & $\mathrm{X}$ & $\mathrm{X}$ \\
\hline \multirow{2}{*}{ 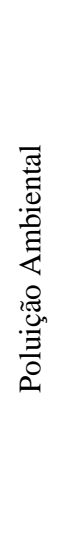 } & Agrotóxicos & $\begin{array}{l}\text { Se referindo aos danos causados } \\
\text { por agrotóxicos, como pesticidas, } \\
\text { inseticidas, herbicidas, fungicidas e } \\
\text { fertilizantes químicos, a } \\
\text { propriedade é livre de danos } \\
\text { causados por agrotóxicos? }\end{array}$ & $\mathrm{X}$ & $X$ & $\mathrm{X}$ \\
\hline & $\begin{array}{l}\text { Queima de } \\
\text { Combustíveis } \\
\text { Fósseis, } \\
\text { Desmatamento, } \\
\text { Descarte } \\
\text { Inadequado de } \\
\text { Dejetos Animais }\end{array}$ & $\begin{array}{c}\text { Se referindo aos fatores que } \\
\text { ocasionam poluição ambiental, e } \\
\text { mudanças climáticas devido aos } \\
\text { gases do efeito estufa, a } \\
\text { propriedade é livre da queima de } \\
\text { combustíveis fósseis, } \\
\text { desmatamento, descarte } \\
\text { inadequado de dejetos animais? }\end{array}$ & $\mathrm{X}$ & $\mathrm{X}$ & $\mathrm{X}$ \\
\hline \multirow[t]{2}{*}{ 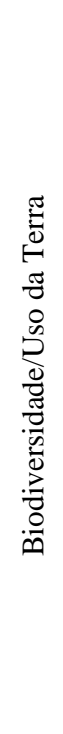 } & $\begin{array}{l}\text { Biodiversidade de } \\
\text { Ecossistemas, } \\
\text { Espécies e a } \\
\text { Diversidade } \\
\text { Genética }\end{array}$ & $\begin{array}{l}\text { Se referindo ao número de } \\
\text { variedade de diferentes seres vivos, } \\
\text { preocupação para proteção das } \\
\text { espécies, habitats e conservação, } \\
\text { como a diversidade genética das } \\
\text { culturas, número de espécies } \\
\text { animais e presença de habitats } \\
\text { naturais como áreas não cultivadas } \\
\text { e lagoas; biodiversidade natural e } \\
\text { agrícola, há biodiversidade de } \\
\text { ecossistemas, espécies e } \\
\text { diversidade genética na } \\
\text { propriedade? }\end{array}$ & $\mathrm{X}$ & $\mathrm{X}$ & $\mathrm{X}$ \\
\hline & $\begin{array}{l}\text { Ocupação da Terra } \\
\text { e os Propósitos de } \\
\text { sua Alocação }\end{array}$ & $\begin{array}{l}\text { Se referindo ao uso do solo, } \\
\text { cobertura florestal, pastagens, } \\
\text { diversidade de cultura, produção } \\
\text { animal, dentre outros, há ocupação } \\
\text { da terra e propósitos para sua } \\
\text { alocação na propriedade? }\end{array}$ & $\mathrm{X}$ & $\mathrm{X}$ & $\mathrm{X}$ \\
\hline 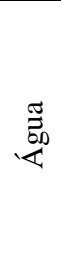 & $\begin{array}{l}\text { Uso ou } \\
\text { Necessidade da } \\
\text { Água }\end{array}$ & $\begin{array}{l}\text { Referente ao uso ou necessidade de } \\
\text { água, o Sr. (a) acredita que às } \\
\text { formas de utilização e a proporção } \\
\text { utilizada, o uso de modo racional e } \\
\text { a tentativa de minimização da } \\
\text { necessidade ocorrem na } \\
\text { propriedade? }\end{array}$ & $\mathrm{X}$ & $\mathrm{X}$ & $\mathrm{X}$ \\
\hline
\end{tabular}




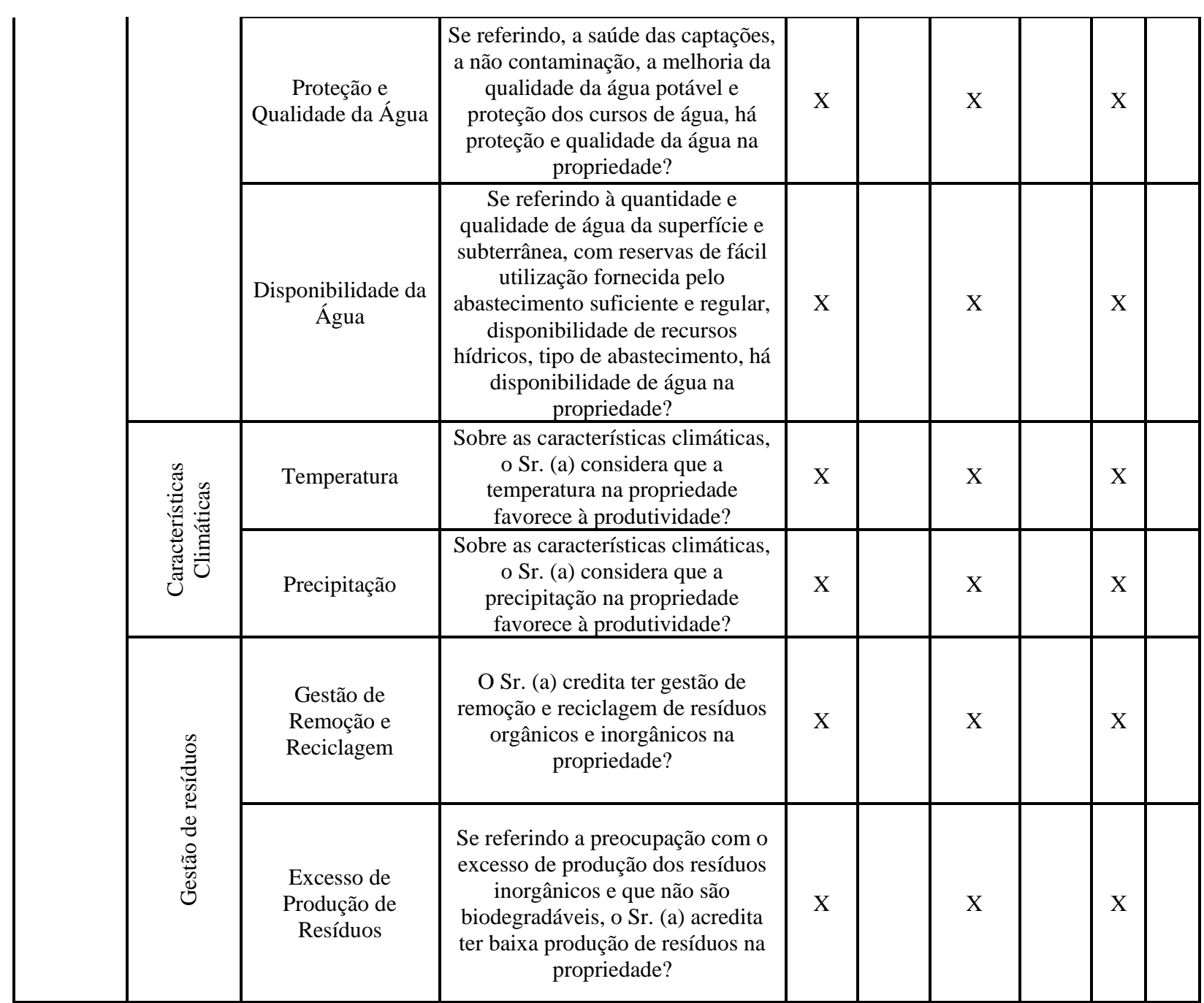

Fonte: Elaborado pelos autores (2021).

O indicador ocupação da terra e os propósitos de sua alocação, de acordo com Vian (2020), trata do uso do solo, cobertura florestal, pastagens, diversidade de cultura, produção animal, dentre outros. Sendo assim, percebe-se com a investigação que a ocupação da terra e o propósito para sua alocação na propriedade estão adequados.

O quarto grupo de critérios para a dimensão ambiental é a água, que é composto por três (3) indicadores ambientais que são: o uso ou necessidade da água, a proteção e qualidade da água e a disponibilidade da água.

Sendo assim, o primeiro indicador observado foi o uso ou necessidade da água, o qual, segundo Vian (2020).Nesse sentido as constatações indicam que as formas de utilização e a proporção utilizada, são realizadas de modo racional e ocorrem a tentativa de minimização da necessidade na propriedade. Visto que a água é utilizada, somente o necessário, buscando-se moderar o consumo para uso pessoal e animais e reaproveitando sempre que possível, evitando o desperdício.

Quanto a proteção e qualidade da água, busca-se verificar se ela está presente na propriedade estudada. Com isso, a partir da investigação verifica-se que a saúde das captações, a não contaminação, a melhoria da qualidade da água potável e a proteção dos cursos de água, é uma preocupação do gestor da propriedade, o qual tem se empenhado com bastante afinco para proteger e qualidade da água na propriedade.

Finalizando este grupo de critérios, foi observado a disponibilidade da água. Nesse sentido, o gestor menciona haver disponibilidade de água na propriedade, considerando a existência de boa quantidade e qualidade de água da superfície e subterrânea, com reservas de fácil utilização fornecida pelo abastecimento suficiente e regular, disponibilidade de recursos 
hídricos e tipo de abastecimento.

No quinto grupo de critérios para a dimensão ambiental é tratado das características climáticas, sendo observado neste grupo dois (2) indicadores ambientais que são: a ttemperatura e precipitação.

No que se refere a temperatura, nota-se a partir da investigação que a temperatura favorece a produtividade na propriedade, considerando a forma com que acontece o manuseio dos recursos, sejam os naturais ou os insumos e práticas necessárias para a realização da atividade económica. Com relação a precipitação, também é considerada pelo gestor que a propriedade favorece à produtividade.

Para finalizar a dimensão ambiental tem-se o grupo de critérios gestão de resíduos, neste grupo são considerados dois (2) indicadores ambientais, que são: a gestão de remoção e reciclagem e o excesso de produção de resíduos. Nota-se que a gestão de remoção e reciclagem de resíduos orgânicos e inorgânicos na propriedade é uma prática existente na propriedade. Uma vez que o gestor menciona que os resíduos sejam eles orgânicos ou inorgânicos são descartados de forma correta. As seringas que são utilizadas para fazer a vacinação das vacas, tanto como sacos de pastagens, são separados segundo os indicativos de segurança e entregue para os coletores de lixo.

Ao finalizar a observação dos indicadores de sustentabilidade, em específicos os da dimensão ambiental, é verificado o excesso de produção de resíduos. Para tanto, o estudo indica a existência de preocupação com o excesso de produção dos resíduos inorgânicos e que não são biodegradáveis. Porém, a partir da perceção do gestor é baixa a produção de resíduos na propriedade.

O Quadro 4 apresenta um consolidado dos números de indicadores pesquisados, e os indicadores encontrados no estudo.

Quadro 4 - Sustentabilidade da propriedade.

\begin{tabular}{|l|c|c|c|c|}
\hline Dimensões & NI & IE & \% & \% média \\
\hline Econômica & 22 & 13 & 59,09 & 19,70 \\
\hline Social & 21 & 12 & 57,14 & 19,05 \\
\hline Ambiental & 16 & 16 & 100,00 & 33,33 \\
\hline Sustentabilidade da propriedade & & & $\mathbf{7 2 , 0 8}$ \\
\hline
\end{tabular}

NI - Número de indicadores; IE - Indicadores encontrados. Fonte: Autores (2021).

Com isso, foram observados na propriedade estudada, práticas dos 16 indicadores de sustentabilidade ambiental, proposto pelo modelo de Vian (2020), o que indica uma sustentabilidade para a dimensão ambiental de $100 \%$. Sendo assim, ao considerar pesos semelhantes entre as três dimensões de sustentabilidade (econômica, social e ambiental), de acordo com Elkington (1997), esta representatividade é de 33,33\%.

A sustentabilidade preconizada por Vian (2020), indica o equilíbrio entre as dimensões econômicas, sociais e ambientais. Sendo que quanto maior os níveis de sustentabilidade para cada dimensão e geral, maior o alinhamento dos indicadores pertencentes a cada dimensão com o que prevê a teoria a respeito do tema.

Vale destacar que para a propriedade rural investigada, os indicadores de sustentabilidade de cada uma das dimensões observada (econômica, social e ambiental) foram semelhantes para ambas as atividades econômicas analisadas, com isso, entende ser desnecessários abordá-las neste tópico, de forma individualizada.

No que se refere aos indicadores econômicos, tem-se dos 22 indicadores de observados, os quais são propostos pelo modelo de Vian (2020), foram constatados 13, indicando que 59,09\% dos indicadores desta dimensão, estão presentes no caso estudado, indicando assim, que a sustentabilidade econômica está próxima de $60 \%$. Sendo que ao atribuir o mesmo peso a esta 
dimensão em comparação com as demais (social e ambiental) (Elkington, 1997), esta representatividade foi de 19,70\%.

Dos 21 indicadores de sustentabilidade social, proposto pelo modelo de Vian (2020), foram constatados 12 indicadores na organização estudada, representando uma sustentabilidade para a dimensão social de 57,14\%. Nota-se, ao considerar pesos semelhantes entre as três dimensões de sustentabilidade (econômica, social e ambiental), de acordo com o sugerido por (Elkington, 1997), esta representatividade é de 19,05\%.

Ainda, para a dimensão ambiental, foram observados na propriedade estuda, a existencia de práticas referentes aos 16 indicadores desta dimensão, proposto pelo modelo de Vian (2020), o que representa que a sustentabilidade para a dimensão ambiental é de $100 \%$. Com isso, ao considerar pesos semelhantes entre as três dimensões de sustentabilidade (econômica, social e ambiental), de acordo com Elkington (1997), esta representatividade é de 33,33\%.

Logo ao analisar a sustentabilidade geral da propriedade, constatou-se que tais achados são semelhantes aos estudos de Vian (2020), ficando em torno de 72,08\%. Tal representatividade é possível, visto que todas as ter dimensões analisadas (econômica, social e ambiental), quando observadas de forma individual foram superiores a 50\%, havendo um destaque para a dimensão ambiental, em que a sustentabilidade foi de $100 \%$.

Nesse sentido, entende-se que saber em que medida os indicadores de sustentabilidades de cada dimensão estão presentes nas atividades econômicas da propriedade rural investigada pode auxiliar quanto a melhoria dos processos de produção, assim como na tomada de decisão com relação a melhorar os seus controles econômicos e financeiros e seus indicadores socioambientais.

\section{Conclusão}

O MASPPR serve para avaliar a sustentabilidade das pequenas propriedades rurais a partir de comparações de uma avaliação que é fornecida por especialistas para cada um dos cinquenta e nove critérios que estão contemplados na sua estrutura em relação a avaliação que foi realizada na pequena propriedade rural. As informações das pequenas propriedades rurais foram levantadas através de uma pesquisa qualitativa elaborada com a estruturada do MASPPR. As informações foram elaboradas com o auxílio da ferramenta linguística 2-tuple, esse instrumento serve para determinar a distância entre os conceitos que são de referência para cada um dos critérios de sustentabilidade do MASPPR e o conceito que foi obtido nas pequenas propriedades rurais.

A parte teórica do MASPPR é um modelo que possibilitou um amplo conjunto de opções (critérios) que podem servir de auxílio para desenvolver novos modelos para fazer a avaliação das pequenas propriedades rurais. Na pratica o MASPPR serviu como um feedback aos gestores da pequena propriedade rural e para os gestores públicos na aplicação do modelo, a fim de implementar as propostas sugeridas e reaplicar o modelo na análise de novos resultados.

Através da identificação dos indicadores de sustentabilidade por atividade econômica da propriedade rural e a intensidade das práticas de sustentabilidade a partir dos pilares sociais, ambientais e econômicos foi possível analisar a sustentabilidade geral da propriedade, constatou-se que tais achados indicam sustentabilidade da propriedade, em torno de 72,08\%. Tal representatividade é possível, visto que todas as ter dimensões analisadas (econômica, social e ambiental), quando observadas de forma individual foram superiores a 50\%, havendo um destaque para a dimensão ambiental, em que a sustentabilidade foi de $100 \%$.

Os indicadores de sustentabilidade podem auxiliar os produtores rurais a promover melhorias nos processos de gestão e desempenho de modo a torná-las mais sustentáveis, e de posse destas informações é possível identificar a medida dos indicadores de sustentabilidade de cada dimensão, e de que forma estes indicadores estão presentes nas atividades econômicas da propriedade rural, auxiliando tanto na melhoria dos processos de produção, como na tomada de decisão através dos controles econômicos e financeiros e seus indicadores socioambientais. 


\section{Referências}

Ahmed, A. \& Mcquaid, R. (2005). Entrepreneurship, management, and sustainable development. World Review of Entrepreneurship, Management and Sustainable Development, 1, (1), 6-30. 10.1504/WREMSD.2005.007750

Bauer, M. W. (2002). Análise de conteúdo clássica: uma revisão. In: M. W. Bauer \& G. Gaskell (Orgs.). Pesquisa qualitativa com texto, imagem e som: um manual prático (Tradução de Pedrinho A. Guareschi). Vozes.

Bellen, H. M. V. (2006). Indicadores de sustentabilidade: uma análise comparativa. (2a ed.), Editora FGV.

Beuren, I. M. et al. (2004). Como elaborar Trabalhos Monográficos em Contabilidade. (2a ed.), Atlas.

Boff, L. (2015). A intolerância no Brasil atual e no mundo. Jbbonline.

Carvalho, A.C.V. \& Stefano, S.R; Munck, L. (2015). Competências voltadas à sustentabilidade organizacional: um estudo de caso em uma indústria exportadora. Gestão \& Regionalidade, 31, (91), 33-48). http://seer.uscs.edu.br/index.php/revista_gestao/article/view/2278/1712.

Du Pisani, J.A. (2006). Sustainable development - historical roots of the concept. Environmental Sciences, 3, (2), 83-96. 10.1080/15693430600688831.

Dyllick, T. \& Hockerts, K. (2002). Beyond the business case for corporate sustainability. Business strategy and the environment. 11, (2), 130-141. doi:10.1002/bse.323.

Elkington, J. (1997). Cannibals with forks: the triple bottom line of 21st century business. Capstone Publishing.

Elkington, J. (2001). The triple bottom line for 21 st century business. The Earthscan reader in business and sustainable development. 20-43. https://www.johnelkington.com/archive/TBL-elkington-chapter.pdf

Ferreira, A.C.S. (2002). Contabilidade ambiental. In: SCHMIDT, Paulo. Controladoria: agregando valor para a empresa. Bookman.

Foladori, G. \& Tommasino, H. (2000). El concepto de desarrollo sustentable treinta años después. Desenvolvimento $e$ Meio Ambiente, 1. http://dx.doi.org/10.5380/dma.vli0.3056

Garcia, D.S.S. (2016). Dimensão econômica da sustentabilidade: uma análise com base na economia verde e a teoria do decrescimento. Veredas do Direito: Direito Ambiental e Desenvolvimento Sustentável. 13(25). 133-153. https://doi.org/10.18623/rvd.v13i25.487

Garcia, E. (1999). El trampolim faustico: Ciencia, mito y poder en el desarollo sostenible. Tilde.

Gil, A.C. (2017). Como elaborar projetos de pesquisa. 6. Atlas.

Gil, A.C. (1999). Métodos e Técnicas de Pesquisa Social. (5a ed.), Atlas.

Jamali, D. (2006). Insights into the triple bottom line integration from a learning organization perspective. Business Process Management Journal. 12, (6). 809-821. http://dx.doi.org/10.1108/14637150610710945.

Labuschagne, C. \& Brent, A.C \& Van Erck, R. P. (2005). Assessing the sustainability performances of industries. Journal of cleaner production. 13, (4). 373385. http://dx.doi.org/10.1016/j.jclepro.2003.10.007.

Labuschagne, C. \& Brent, A. C. \& Van Erck, R. P. (2004). Assessing the sustainability performances of industries. Journal of Cleaner Production. 1-13. https://www.semanticscholar.org/paper/Assessing-the-sustainability-performances-of-Labuschagne-Brent/e $8747 \mathrm{cb} 3 \mathrm{ba358cd} 8 \mathrm{c} 512 \mathrm{bd} 51$ faad473bebc65b22.

Lorenzetti, D. H. Cruz, R. M. \& Ricioli, S. (2008). Estratégia empresarial e sustentabilidade: um modelo integrador. Revista da Pós-graduação: Administração, 2, (3), 33-57. http://www.spell.org.br/documentos/ver/31280/em.

Maas, K. Schaltegger, S. \& Crutzen, N. (2016). Integrating corporate sustainability assessment, management accounting, control, and reporting. Journal of Cleaner Production. 136, (1). 237-248. https://www.scirp.org/(S(czeh2tfqyw2orz553k1w0r45))/reference/ReferencesPapers.aspx?ReferenceID=1815117

Marconi, M. A. \& Lakatos, E. M. (2003). Fundamentos de metodologia científica. 5. Atlas.

Martins, E. F. \& Guimarães, G. M. A. (2002). As concepções de natureza nos livros didáticos de ciências. Ensaio Pesquisa em Educação em Ciências (Belo Horizonte). 4, (2). 101-114. https://www.scielo.br/j/epec/a/dxY689YjtppkjjQDfW7yDJg/?format=pdf\&lang=pt.

Merriam, S. B. (1998). Qualitative research and case study applications in education. Jossey-Bass.

Munck, L. \& Munck, G. M. \& Souza, R. B. (2011). Sustentabilidade organizacional: a proposição de uma framework representativa do agir competente para seu acontecimento. Gerais: Revista Interinstitucional de Psicologia. 4.SPE. 147-158. http://pepsic.bvsalud.org/scielo.php?script=sci_arttext\&pid=S198382202011000300005 .

Munck, L. \& Souza, R. B. (2012). Análise das inter-relações entre sustentabilidade e competências: um estudo em uma indústria do setor eletroeletrônico. Base - Revista de Administração e Contabilidade da UNISINOS. 9, (3). São Leopoldo: Universidade do Vale do Rio dos Sinos.

Munck, L. \& Munck, M. G. M. \& Borim-De-Souza, R. (2011). Sustentabilidade organizacional: a proposição de uma framework representativo do agir competente para seu acontecimento. Gerais: Revista Interinstitucional de Psicologia. 4, SPE, 147-158. https://docs.bvsalud.org/biblioref/2018/03/880863/v4nspea05.pdf.

Oliveira, S. G. (2007). Indenizações por Acidente do Trabalho ou Doença Ocupacional. LTR. 
Research, Society and Development, v. 11, n. 2, e47511224628, 2022

(CC BY 4.0) | ISSN 2525-3409 | DOI: http://dx.doi.org/10.33448/rsd-v11i2.24628

Oliveira, A. F. S. et al. (2007). A sustentabilidade da agricultura orgânica familiar dos produtores associados à APOI (Associação dos Produtores Orgânicos da Ibiapaba-CE). Dissertação de Mestrado em Desenvolvimento e Meio Ambiente. Ceará: Universidade Federal do Ceará.

Oliveira, D. P. R. (1996). Sistemas de informações gerenciais. 3. Atlas.

Oliveira, T. A. et al. (2004). Avaliação institucional. Cadernos temáticos: avaliação institucional. SEED.

Ponte, V. M. R. et al. (2007). Análise das práticas de evidenciação de informações obrigatórias, não-obrigatórias e avançadas nas demonstrações contábeis das sociedades anônimas no Brasil: um estudo comparativo dos exercícios de 2002 e 2005. Revista Contabilidade \& Finanças. 18, (45). 50-62. https://doi.org/10.1590/S1519-70772007000400005

Potrich, R. Grzybovski, D. \& Toebe, C. S. (2017). Sustentabilidade nas pequenas propriedades rurais: um estudo exploratório sobre a percepção do agricultor. Estudos Sociedade e Agricultura. 25, (1). https://doi.org/10.36920/esa-v25n1-9.

Prodanov, C. C. \& Freitas, E. C. (2013). Metodologia do Trabalho Científico: Métodos e Técnicas da Pesquisa e do Trabalho Acadêmico. 2, Novo Hamburgo: Associação Pró-Ensino Superior em Novo Hamburgo - ASPEUR Universidade Feevale. http://www.feevale.br/Comum/midias/8807f05a-14d0-4d5b-b1ad1538f3aef538/E-book \%20Metodologia\%20do\%20Trabalho\%20Cientifico.pdf.

Sachs, I. (1993). Estratégias de transição para o século XXI. In: BURSZTYN, M. Para Pensar o Desenvolvimento Sustentável. Brasiliense.

Sanches, C. S. (1997). Evolução das práticas ambientais em empresas industriais: um modelo genérico. In Anais IV Encontro Nacional sobre Gestão Empresarial e Meio Ambiente. São Paulo. https://doi.org/10.1590/S1519-70772001000300007.

Santos, J. V. \& Ferreira, R. C. (2011). Planejamento Ambiental. Instituto Federal do Paraná.

Schneider, S. (2016). A Presença e as Potencialidades da Agricultura Familiar na América Latina e no Caribe. Revista do Desenvolvimento Regional. 21, (3), 11-33, https://doi.org/10.17058/redes.v21i3.8390.

Tachizaw, É. T. (2005). Gestão Ambiental e Responsabilidade Social Corporativa: Estratégia de Negócios Focadas na Realidade Brasileira. 3. Atlas.

Vian, A. Z. (2020). Modelo de avaliação da sustentabilidade de pequenas propriedades rurais: uma abordagem multicritério linguística. Dissertação de Mestrado. Universidade Tecnológica Federal do Paraná. https://repositorio.utfpr.edu.br/jspui/handle/1/5071.

Werbach, A. (2010). Estratégia para sustentabilidade: uma nova forma de planejar sua estratégia empresarial. Elsevier.

Wrigley, E. A. (2013). Energy and the English industrial revolution. Phil. Trans. R. Soc. A, 371(1986). https://doi.org/10.1098/rsta.2011.0568.

Yin, R. K. (2001) Estudo de caso: planejamento e métodos. Bookman. 